\title{
Polyurethane cationomers containing fluorinated soft segments with hydrophobic properties
}

\author{
Piotr Król $^{1} \cdot$ Kinga Pielichowska ${ }^{2} \cdot$ Bożena Król $^{1} \cdot$ Katarzyna Nowicka $^{2} \cdot$ Małgorzata Walczak $^{1} \cdot$ Małgorzata Kowal $^{1}$
}

Received: 8 May 2020 / Revised: 14 January 2021 / Accepted: 22 January 2021 / Published online: 22 February 2021

(C) The Author(s) 2021

\begin{abstract}
The synthesis of ecological waterborne polyurethane cationomers containing fluorinated polyol (0-20 wt.\%) was successfully performed. FTIR and NMR analysis results confirmed the structure of the obtained polyurethane cationomers and incorporation of fluorinated component into the polyurethane chains. Average molar mass and phase structure of the obtained PU thin films were determined based on GPC, FTIR, WAXD and SEM-EDX results. The obtained cationomers have linear structures with clearly visible microphase separation of soft and hard segment domains; the presence of fluorinated polyol changes the strength of hydrogen bonds and in consequence degree of phase separation. The activation energy of glass transition was calculated based on multi-frequency DSC data. It has been shown that the presence of soft fluorinated segments in the cationomer structure strongly influences the hydrophobic, thermal and mechanical properties of the obtained films.
\end{abstract}

Keywords Water ecological dispersions $\cdot$ Fluorinated polyols $\cdot$ Surface properties $\cdot$ Mechanical and thermal properties

\section{Introduction}

Coatings and films based on polyurethanes modified with fluorinated compounds are currently subject of wide interest due to their hydrophobic character and unique properties [1-5]. Recently, research attention was dedicated to fluorinecontaining waterborne polyurethanes for ecological varnishes [6-11]. The fluorine-containing polyurethane coatings, characterized by high hydrophobicity, are less toxic and have favourable properties compared to polyurethane varnishes based on organic solvents or solvent-free systems containing free isocyanates.

Most of the works on these materials is related to the use of polyurethane anionomers in waterborne products, while much less attention is given to cationomers [12]. However, our analysis shows that the cationomers' application potential has not

Piotr Król

pkrol@prz.edu.pl

1 Faculty of Chemistry, Rzeszow University of Technology, Al. Powstańców Warszawy 6, 35-959 Rzeszów, Poland

2 Department of Biomaterials and Composites, Faculty of Materials Science and Ceramics, AGH University of Science and Technology, Al. Mickiewicza 30, 30-059 Kraków, Poland yet been fully utilized, and the knowledge in this area is still incomplete.

It is known that incorporation of fluorine atoms to polyurethane structure (PU) leads to weakening of intermolecular interactions and, in consequence, to changes in morphology due to significant decrease of phase separation [13]. Such an effect makes the mechanical properties worsen, but improve the thermal stability and decrease the free surface energy (FSE). It can be explained by the migration of fluorinecontaining segments towards the surface which results in hydrophobicity increase, as well as friction reduction on the PU elastomer surface [5]. The presence of fluorine atoms also cause higher chemical and corrosion durability of the PU coatings and higher environmental resistance [10, 14]. Fluorinated $\mathrm{PU}$ is also an interesting material for medical applications [15]. In in vitro cytocompatibility tests of fluorinated PU, athrombogenicity and limited cytotoxicity have been confirmed. Such properties, desired for polymeric biomaterials, result from significant hydrophobicity of fluorinated PU coatings.

In a most frequently used approach, fluorine atoms are incorporated into polyurethane structure by using tetrafluorobutanediol (TFBD) as effective low molecular chain extender. This preparation method is used for both elastomers and polyurethane anionomers, as well as for waterborne polyurethanes. However, the effect of $\mathrm{F}$ atoms on 
selected properties of films and coatings made of polyurethane cationomers still needs to be explained in a broader context. In comparison to anionomers, in polyurethane cationomers, there are many possibilities of structural modifications, e.g., by chemical changes in hard segments structure (by using tertiary amines) as well as by using of fluorine modified soft segments that leads to different location of fluorine atoms.

TFBD in polyurethane structure is generally located in hard segments. Fluorinated polyether diol (FPD) as polyol with higher molar mass and PCL, that is more hydrophobic than e.g. poly(ethylene adipinate) can form more hydrophobic soft phase. Due to the higher mass ratio of soft segments in polyurethane structure, it is expected that incorporation of fluorine atoms in polyol leads to formation of more hydrophobic polyurethane films and coatings with proper elastic properties typical for polyurethane-based elastomers.

In our previous work [16], properties of a fluorinecontaining polyurethane cationomer, in which fluorine atoms were incorporated into the hard segments derived from the isocyanate prepolymer-poly(tetrafluoroethylene oxide-co-difluoromethylene oxide) $\alpha, \omega$-diisocyanate (PF) were presented. It has been shown that the presence of fluorine atoms causes a reduction in free surface energy (FSE). Moreover, our empirical mathematical models have predicted that the incorporation of 2,2,3,3-tetrafluoro-1,4butanediol together with NMDA or $N$-butyldiethanolamine into the rigid segments of the cationomers synthesized based on 4,4'-methylenebis(phenyl isocyanate) (MDI) or isophorone diisocyanate (IPDI) and PEG (600) shall lead to a significant decrease in FSE [17]. The open question is what kind of effect will be observed after the incorporation of fluorine-containing compounds to soft segments and how it will affect the thermal and mechanical properties of coatings and films based on polyurethane cationomers. The results presented in the literature, e.g. utilizing small molecules containing fluorine atoms like 2,2,3,3tetrafluoro-1,4-butanediol or $1 \mathrm{H}, 1 \mathrm{H}, 10 \mathrm{H}, 10 \mathrm{H}$-perfluoro1,10-decane diol in hard segments $[18,19]$, or soft segments formed by using fluorine-containing polyols [1], do not allow to answer fully this question.

Therefore, in our research, fluorinated polyether diol (FPD) and poly(E-caprolactone) diol (PCL) were used for preparation of PU films, with MDI and IPDI being used as isocyanate components. In this case, in such synthesized PUs, fluorine was located in the soft segments. In contrast, hard segments form urethane and ionic groups: alkylammonium cations (from NMDA) and $\mathrm{HCOO}^{-}$as counterions were used. The results of structural tests of the obtained films were presented, and the impact of fluorine on surface, thermal and mechanical properties were discussed towards future applications in e.g. biomedical field.

\section{Experimental section}

\section{Reagents}

4,4'-Methylenebis(phenyl isocyanate) purity $98 \%$ (MDI) and isophorone diisocyanate (mixture of cis- and trans-isomers, purity 98\%) (IPDI), poly( $\varepsilon$-caprolactone) diol, (PCL 2000), characterized by $M_{\mathrm{n}}=2464, M_{\mathrm{w}}=4747$ and $M_{\mathrm{w}} / M_{\mathrm{n}}$ $=1.93 ; N$-methyl diethanolamine $($ MDEA) purity $99 \%$; and 1,6-hexamethylenediamine (HDA) purity $98 \%$, benzoyl chloride (inhibitor), purity $98 \%$ from Sigma-Aldrich were used. Also analytical reagents like dibutyl amine, diiodomethane and formamide were supplied by SigmaAldrich.

PolyFox 636 fluorinated polyether diol (FPD) with $\mathrm{OH}$ Number $\mathrm{LOH}=94 \mathrm{mg} \mathrm{KOH} / \mathrm{g}$ was purchased from Omnova (USA) (Formula 1).

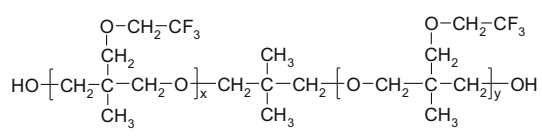

Formic acid ( $\mathrm{HCOOH} ; 99 \%$;) and tetrahydrofuran (THF) purity $99 \%$ were products of POCh (Poland). Dibutyltin dilaurate (DBTL) purity $95 \%$ catalyst was obtained from Huntsman Performance Chemicals. Before synthesis, PCL and FPD were dried under vacuum at 120 ${ }^{\circ} \mathrm{C}$ for $4 \mathrm{~h}$.

\section{Synthesis method of the urethane cationomer films}

Cationomers were synthesized in a glass system composed of three-necked flask, heating bowl, mechanical stirrer, dropping funnel, thermometer, reflux condenser and nitrogen supply nozzle.

Stage 1: Prepolymerization in THF solution

As first stage, urethane-isocyanate prepolymer was synthesized in the reaction of MDI or IPDI diisocyanate $(B)$, and $\mathrm{PCl}$ $\left(A_{1}\right)$ and FPD $\left(A_{2}\right)$, Eq. 2:

$3 B+A_{1}+A_{2} \rightarrow B A_{1} B A_{2} B$

Stoichiometric amounts of reagents were selected to obtain the planned fluorine concentrations in subsequent samples and obtain the required sample mass (Table 1).

Sample designations: Series A refers to $\mathrm{PU}$ cationomers synthesized using MDI; series B were obtained from IPDI. The number " 10 " indicates the 


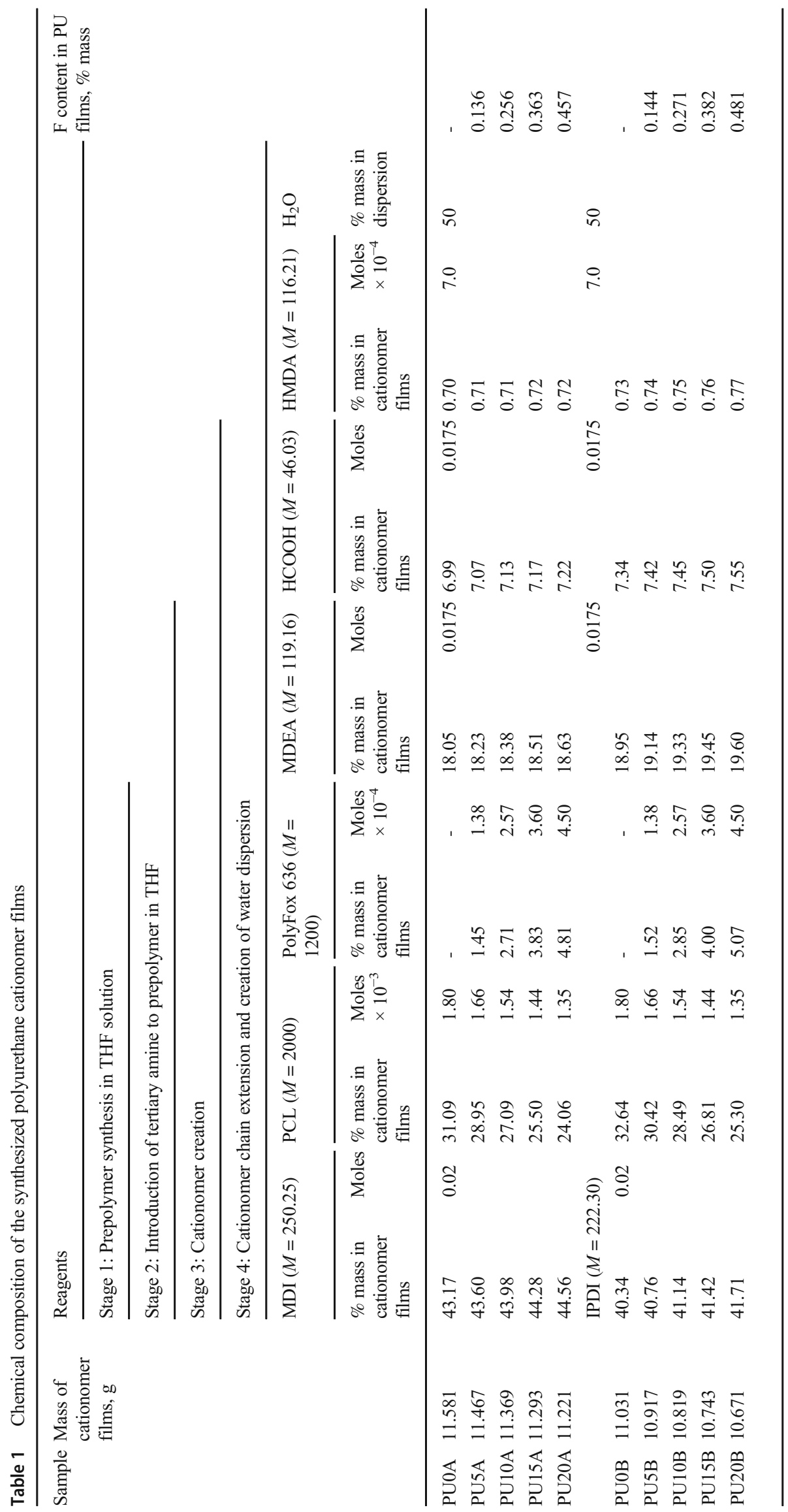


percent mass ratio of FPD to PCL in the soft segments of the PU cationomer.

For example, PU10A sample preparation route:

Stage 1: $\quad 5.00 \mathrm{~g}(0.02 \mathrm{~mol})$ of MDI and $0.01 \mathrm{~g}$ of benzoyl chloride were dissolved in $27 \mathrm{~mL}$ of THF which has been heated up to $50{ }^{\circ} \mathrm{C}$. Then, $3.08 \mathrm{~g}$ $(0.00154 \mathrm{~mol})$ of PCL with $0.308 \mathrm{~g}(0.000257$ mol) FPD diol was dropped for 10 min to prepared solution. Benzoyl chloride was added to inhibit the side reaction which yielded in allophanate groups.

Stage 2: Chain extension

At stage 2, the prepolymer was reacted with $\operatorname{MDEA}(X)$, Eq. 3:

$n B A_{1} B A_{2} B+n X \rightarrow-\left(X B A_{1} B A_{2} B\right)_{\mathrm{n}}$

as a result of tertiary amino groups were incorporated into the polyurethane chains. During synthesis, $2.09 \mathrm{~g}$ $(0.0175 \mathrm{~mol})$ of MDEA (dissolved in $20 \mathrm{~mL}$ of THF) was added to the flask at $50{ }^{\circ} \mathrm{C}$, and the flask was maintained at that temperature over $30 \mathrm{~min}$. After that time, the analysed content of $-\mathrm{NCO}$ groups was close to $0 \%$.

Stage 3: Neutralization

Alkylammonium cations were obtained in reaction of tertiary amino groups from MDEA with $\mathrm{HCOOH}$. To obtain material with proper molar ratio of built-in tertiary amine in PU, $0.0081 \mathrm{~g}(0.0175 \mathrm{~mol})$ of $\mathrm{HCOOH}$ was added to the mixture. The mass fraction of $\mathrm{NH}^{+}$groups in obtained cationomers resulted from the stoichiometry. The reaction with $\mathrm{HCOOH}$ was conducted at $50{ }^{\circ} \mathrm{C}$ during $2 \mathrm{~h}$, and then it has been continued for $6 \mathrm{~h}$ at ambient temperature.

\section{Stage 4: Dispersion}

Redistilled water $(12 \mathrm{~mL})$ with a small amount of 1,6-hexamethylenediamine (HMDA) was added under intensive stirring to remove the residual $-\mathrm{NCO}$ groups. The detailed chemical composition of the obtained cationomer films is shown in Table 1.

Polymer films for further testing were prepared by pouring aqueous dispersions onto a non-polar surface of poly(tetrafluoroethylene) (PTFE) and evaporating water in a vacuum dryer at $80{ }^{\circ} \mathrm{C}$ for $8 \mathrm{~h}$. Before removing from
PTFE plates, the films were seasoned at $20^{\circ} \mathrm{C}$ for 10 days.

\section{Characterization techniques}

\section{Infrared spectroscopy}

FTIR spectra were recorded on a HATR PIKE attachment with diamond crystal linked to Bruker Vertex 70V FTIR spectrometer. In all cases, 16 scans at a resolution of $2 \mathrm{~cm}^{-1}$ were collected in a range of $4000-650 \mathrm{~cm}^{-1}$.

FTIR spectra in the range $1650-1750 \mathrm{~cm}^{-1}$ were deconvoluted using OPUS software to obtain the peak area of the hydrogen-bonded $\mathrm{C}=\mathrm{O}$ groups at $1694-1712 \mathrm{~cm}^{-1}$ in urethane structures and from the free urethane $\mathrm{C}=\mathrm{O}$ group at $1711-1730 \mathrm{~cm}^{-1}$. Based on deconvolution results, the degree of hydrogen bonding and degree of phase separation in the obtained fluorinated PU have been calculated. The degree of the carbonyl groups participating in hydrogen bonding can be described by the carbonyl hydrogen bonding index $R$ that is given in Eq. (4) [20].

$R=\frac{C_{\text {bonded }} \cdot f_{\text {bonded }}}{C_{\text {free }} \cdot f_{\text {free }}}=\frac{A_{1694-1712}}{A_{1711-1730}}$

where $C$ is the concentration, $A$ is the area of absorption peak and $f$ is the respective extinction coefficient of bonded and free carbonyl groups. The ratio of $f_{\text {bonded }} / f_{\text {free }}$ was taken as 1 according to Seymour et al. [20]. The degree of phase separation (DPS) was calculated using Eq. (5) [20]:

$D P S=\frac{C_{\text {bonded }}}{C_{\text {free }}+C_{\text {bonded }}}=\frac{R}{1+R}$

\section{NMR spectroscopy}

${ }^{1} \mathrm{H}$ and ${ }^{13} \mathrm{C}$ NMR spectra of the obtained PUs were taken with the use of the spectrometer FT NMR Bruker Avance $500^{\mathrm{II}}$. The samples of films were dissolved in DMSO- $\mathrm{d}_{6} / \mathrm{h}-\mathrm{DMSO}$ and the solutions with a concentration of about $0.2 \mathrm{~g} \cdot \mathrm{L}^{-1}$ were prepared. TMS was used as a standard.

\section{GPC chromatography}

The average molecular masses, $M_{\mathrm{n}}, M_{\mathrm{w}}, M_{\mathrm{z}}$ and dispersity $M_{\mathrm{w}} / M_{\mathrm{n}}$ of the products were measured using gel permeation chromatography (GPC) using a RI detector (Shodex RI-71). The GPC instrument was equipped with TSKgel GMHHR-M and TSKgel GMHHR Guard column packed with styrene divinylbenzene-type gel. The measurements were performed at a temperature of $22^{\circ} \mathrm{C}$. All samples were dissolved in $N, N$ dimethylformamide (HPLC grade) containing $5 \mathrm{mmol} \cdot \mathrm{L}^{-1}$ 
$\mathrm{LiCl}$. The flow rate of the carrier solvent was $1.00 \mathrm{~mL} \cdot \mathrm{min}^{-1}$. The sample injection volume was $100 \mu \mathrm{L}$. The average molecular masses and dispersity were determined using OmniSEC software (Dublin, Ireland). Polystyrene standards from Polymer Laboratories were used to make calibration curve.

\section{SEM-EDX}

The SEM microphotographs were carried out using the scanning electron microscope Hitachi S-3400N (SEM). SEM studies were carried out in low vacuum mode (LV) using a backscattered electron detector (BSE); the accelerating voltage was $15 \mathrm{kV}$. The chemical composition was determined by applying the energy-dispersive spectroscopy method (EDX). The results of chemical analysis are shown in the form of Xray spectra (qualitative analysis) and the element content, weight atom \% (quantitative analysis). For investigations, uniform films without visible to the naked eye defects have been selected and used.

\section{DSC and TOPEM DSC}

The Mettler-Toledo DSC 1 calorimeter was used to perform conventional DSC analyses and TOPEM (advanced multifrequency temperature modulated DSC) measurements. It was equipped with intracooler, as well as with STARe software for the control of the experimental conditions and data. In analysis of the conventional measurements, heating rate 10 ${ }^{\circ} \mathrm{C} \cdot \mathrm{min}^{-1}$ was applied while for TOPEM measurements, the underlying heating rate was $2^{\circ} \mathrm{C} \cdot \mathrm{min}^{-1}$, the amplitude of the temperature pulse was $\pm 0.5^{\circ} \mathrm{C}$, and the switching time range to limit the duration of the pulses had the minimum of $15 \mathrm{~s}$ and the maximum of $30 \mathrm{~s}$. The sample mass was ca. $8 \mathrm{mg}$ and the atmosphere was nitrogen $\left(30 \mathrm{~mL} \cdot \mathrm{min}^{-1}\right)$.

\section{Thermogravimetric analysis}

Thermogravimetric analysis (TG) of the polyurethane films was performed using a TG/DSC1 thermoanalyzer from Mettler-Toledo. The measurements were taken within the temperature range of $25-600{ }^{\circ} \mathrm{C}$, at a constant heating rate of $10^{\circ} \mathrm{C} \cdot \mathrm{min}^{-1}$ in nitrogen and a sample mass was $\sim 3 \mathrm{mg}$. Based on TG and DTG curves, the thermal stability of the films was assessed by determining temperatures corresponding to mass loss of $1,5,10$ and $50 \%$.

\section{Wide-angle X-ray diffraction (WAXD)}

WAXD diffractograms were obtained on a low angle Nanostar-U Bruker diffractometer working in transmission geometry with $\mathrm{Cu}$ lamp emitting radiation with a length of $1.54056 \AA$ powered $50 \mathrm{kV}$ voltage and of $600 \mathrm{~mA}$ current.
The device was equipped with a crossed Goebel mirrors which allow to obtain a parallel beam having a diameter of 500 microns. Measurements were made at $20^{\circ} \mathrm{C}$.

\section{Free surface energy}

Physical parameters of the free surface energy (FSE) of a solid $\left(\gamma_{\mathrm{S}}\right)$ were found based on the Owens-Wendt methods [21]. The method assumes that the $\operatorname{FSE}\left(\gamma_{S, L}\right)$ may be presented as a sum of two components:

$\gamma_{S, L}=\gamma_{S, L}^{d}+\gamma_{S, L}^{p}$

where:

$\gamma_{S, L}^{d} \quad$ surface energy connected with dispersion interactions, $\gamma_{S, L}^{p} \quad$ surface energy connected with polar interactions

Equation (7) is generally applicable both to a solid phase (film) (the subscript of "S" is used then) as well as to a wetting liquid (standard liquid with the subscript of "L").

The FSE for solids $(S)$ and liquids $(L)$ interacting with those solids should fulfill the Owens-Wendt Eq. (7):

$\gamma_{L} \cdot \frac{1+\cos \Theta}{2}=\sqrt{\gamma_{S}^{d} \cdot \gamma_{L}^{d}}+\sqrt{\gamma_{S}^{p} \cdot \gamma_{L}^{p}}$

where $\Theta$ is the experimentally found contact angle between a liquid drop and a solid surface under investigation. Therefore, wetting angles $\Theta$ were first measured for the surfaces of polyurethane films with the use of model liquids (waterdiiodomethane) with the known parameters: $\gamma_{L}=72.8 ; \gamma_{L}{ }^{d}$ $=21.8 ; \gamma_{L}{ }^{p}=51.0 \mathrm{~mJ} / \mathrm{m}^{2}$ (for water) and $\gamma_{L}=50.8{\gamma_{L}}^{d}=48.5$ $\gamma_{L}^{p}=2.3 \mathrm{~mJ} / \mathrm{m}^{2}$ (for diiodomethane)

Then, Eq. (8) was used to calculate the values $\gamma_{S}^{p}$ and $\gamma_{S}{ }^{d}$ for the studied polyurethane films. The $\gamma_{\mathrm{S}}$ values were calculated from Eq. (7).

The contact angles $\Theta$ were measured with the use of the method suggested by Zisman [22], i.e. by an optical goniometer (Cobrabid Optica, Warsaw) with a digital camera installed in the axial extension of its lens.

\section{Water uptake}

Water uptake $W$ was calculated according to the equation:

$W(\%)=\frac{m_{m}-m_{s}}{m_{s}} \cdot 100$

where:

$m_{m}$ the mass of the wet sample after immersion in distilled water for $2 \mathrm{~min}$,

$m_{s} \quad$ the mass of the dry sample before immersion 


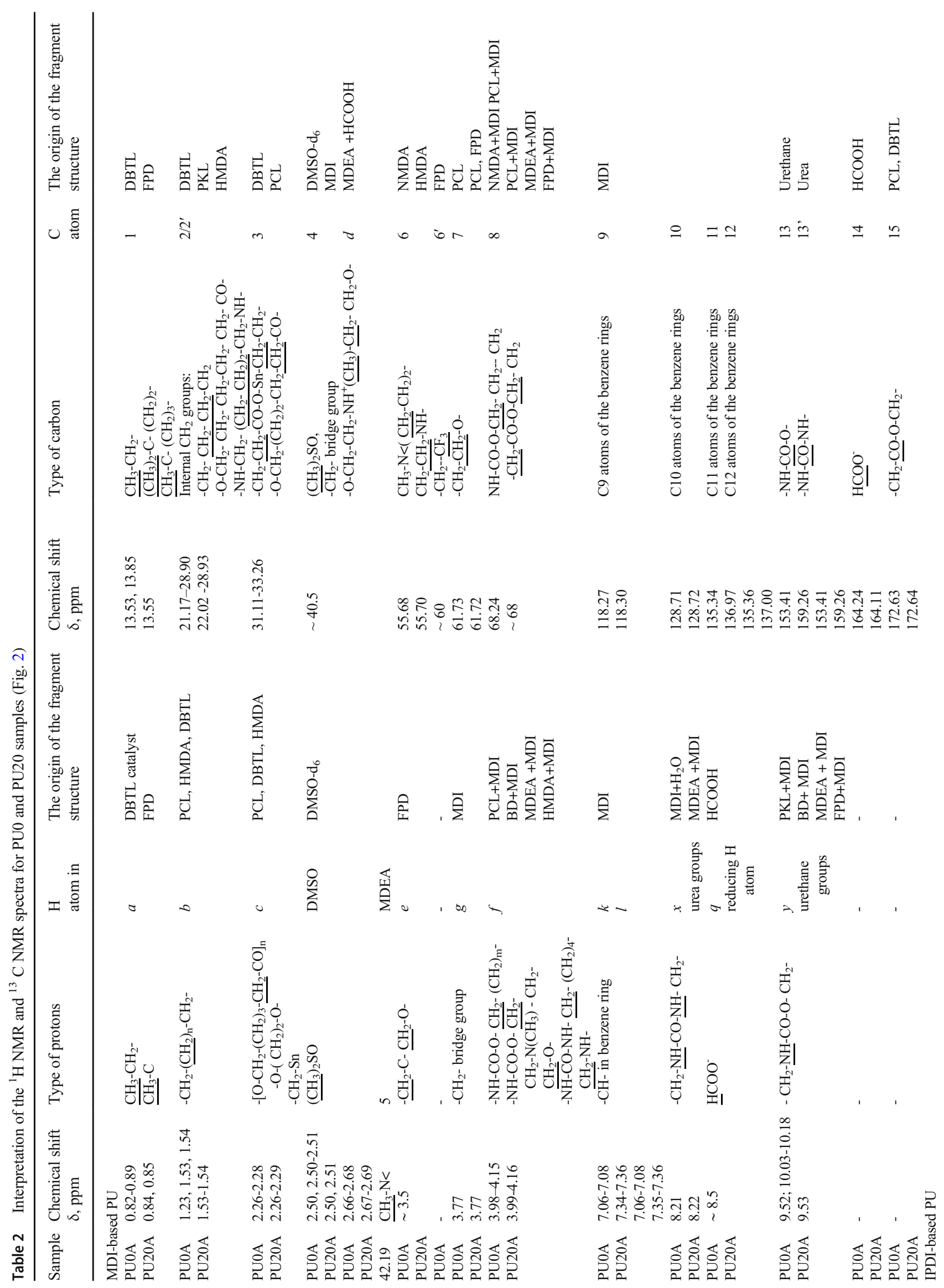




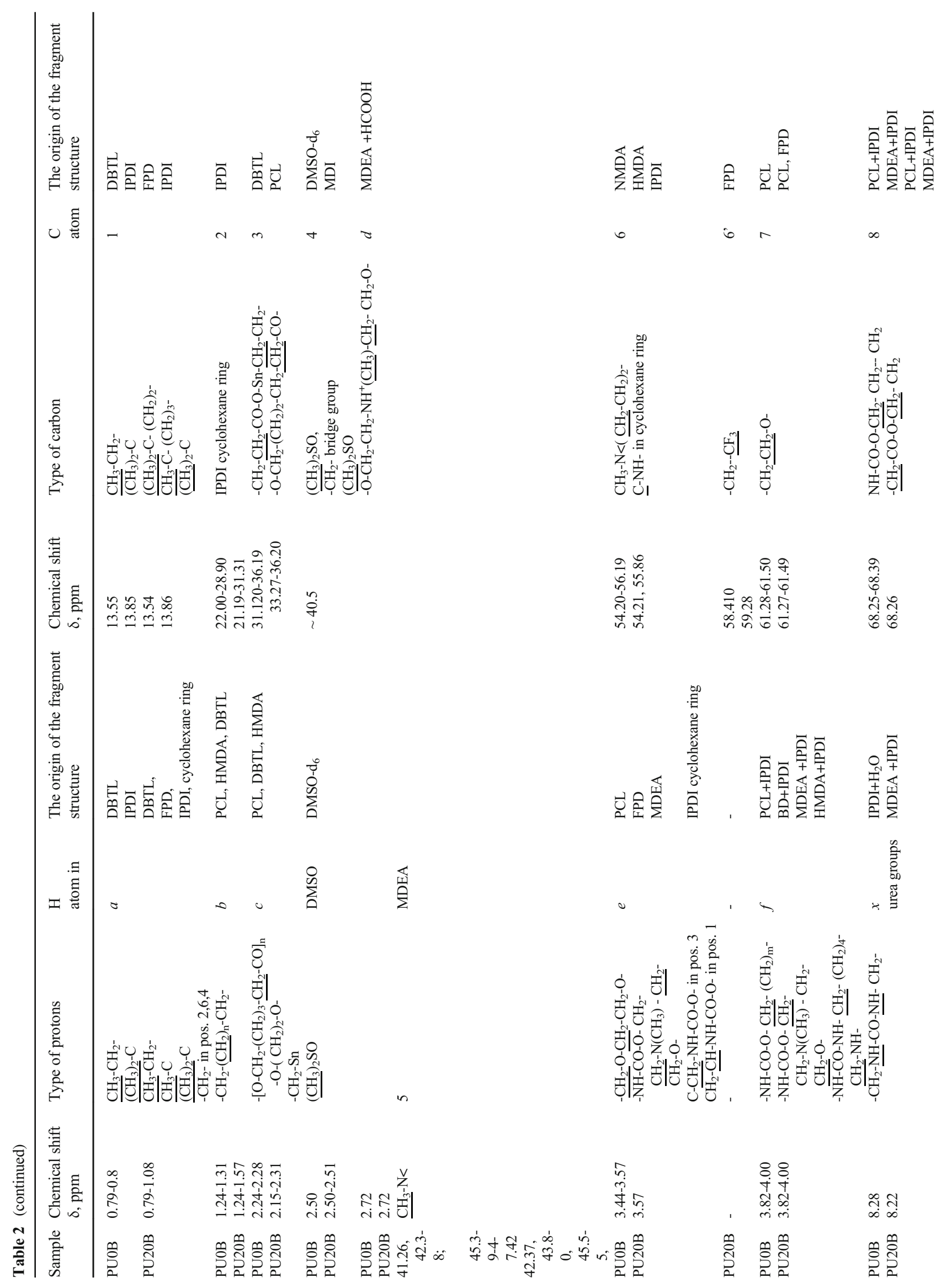




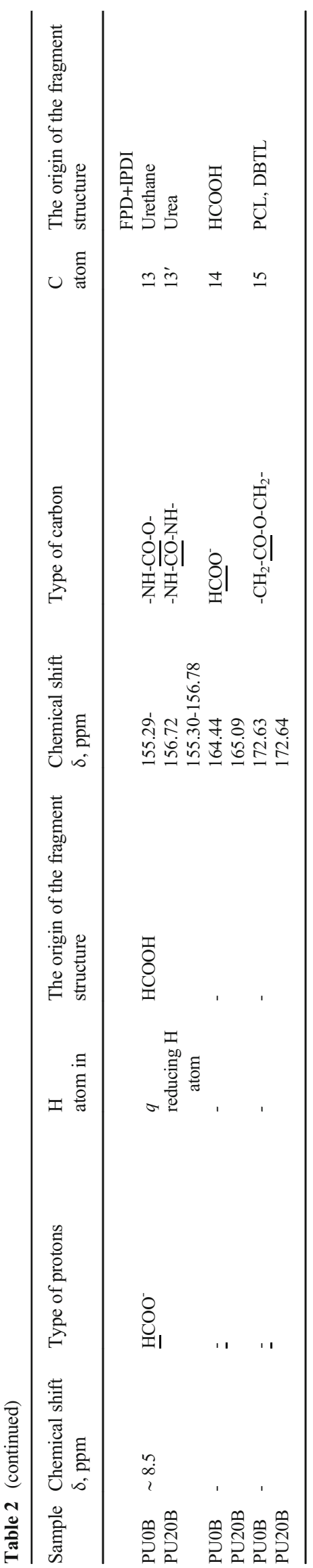

Mechanical properties

Mechanical properties were determined using a testing machine ZWICK type BZ1.0/TH. The speed of sliding jaws of the equipment was $100 \mathrm{~mm} / \mathrm{min}$, sample width-10 $\mathrm{mm}$, measuring length $-50 \mathrm{~mm}$. The following parameters were determined: Young's modulus $(E)$, Stress at break $\left(\sigma_{r}\right)$ and Elongation at break $\left(\varepsilon_{\mathrm{r}}\right)$.

\section{Results and discussion}

\section{Chemical structures and molecular mass distribution}

A useful way to analyse PU structures is to compare the NMR spectra of PU0A or PU0B samples (without fluorine) with the spectra of PU20A and PU20B samples with the largest amount of fluorinated diol. For simplicity, Fig. 1 shows the ${ }^{1} \mathrm{H}$ and ${ }^{13} \mathrm{C}$ NMR spectra of only these cationomers. Signals related to $\mathrm{H}$ (marked with letters) and $\mathrm{C}$ (marked with numbers) were assigned to structures shown in Figs. 1 and 2. Detailed interpretation of ${ }^{1} \mathrm{H}$ and ${ }^{13} \mathrm{C}$ NMR spectra is presented in Table 2.

Signals (a) of the protons of $\mathrm{CH}_{3}-\mathrm{C}$ groups confirmed incorporation of fluorinated diol into $\mathrm{PU}$ chains, they are visible especially in ${ }^{1} \mathrm{H}$ NMR spectra of PU20A, and signal (6') refers to $\mathrm{C}$ atoms of $-\mathrm{CH}_{2}-\mathrm{CF}_{3}$ group observed in ${ }^{13} \mathrm{C}$ NMR spectra in the range $\delta=60 \mathrm{ppm}$. These signals are not present in the spectra of PU0A and PU0B cationomers.

Table 4 shows the analysis of the integration of selected resonances in ${ }^{1} \mathrm{H}$ NMR spectra from PU0A to PU20A cationomers based on MDI. Comparison of Ia/lk integration evidences incorporation of FPD into PU chains - the increase of the Ia/Ik integration ratio indicates the incorporation of an increasing number of segments derived from FPD in contrast to samples where the If/Ik integration ratio does not show regular changes. In each cationomer sample, the amounts of urethane groups are comparable due to the use of equal amounts of MDI in subsequent reactions.

The FTIR spectra, shown in Fig. 3, confirm the structure of the obtained cationomers. Their detailed interpretation is given in Tables 3 and 4. Series A cationomers exhibit aromatic structure, series $\mathrm{B}$, alicyclic. The urethane structure is confirmed by $-\mathrm{NH}$ - and $\mathrm{C}=\mathrm{O}$ bands at 3340,1720 and 1530 $\mathrm{cm}^{-1}$. The lack of the -NCO band at $2260 \mathrm{~cm}^{-1}$ for all of the studied PUs confirmed the complete conversion of the isocyanate reagents. The relatively low content of fluorine in the cationomers is identified by narrow band at the $1280 \mathrm{~cm}^{-1}$ in only PU20A and PU20B spectra. Results of FTIR spectra deconvolution are presented on the example of PU20A and PU20B spectra (Fig. 4), while the results of the calculation of the degree of phase separation (DPS) for all samples are given in Table 5 . 

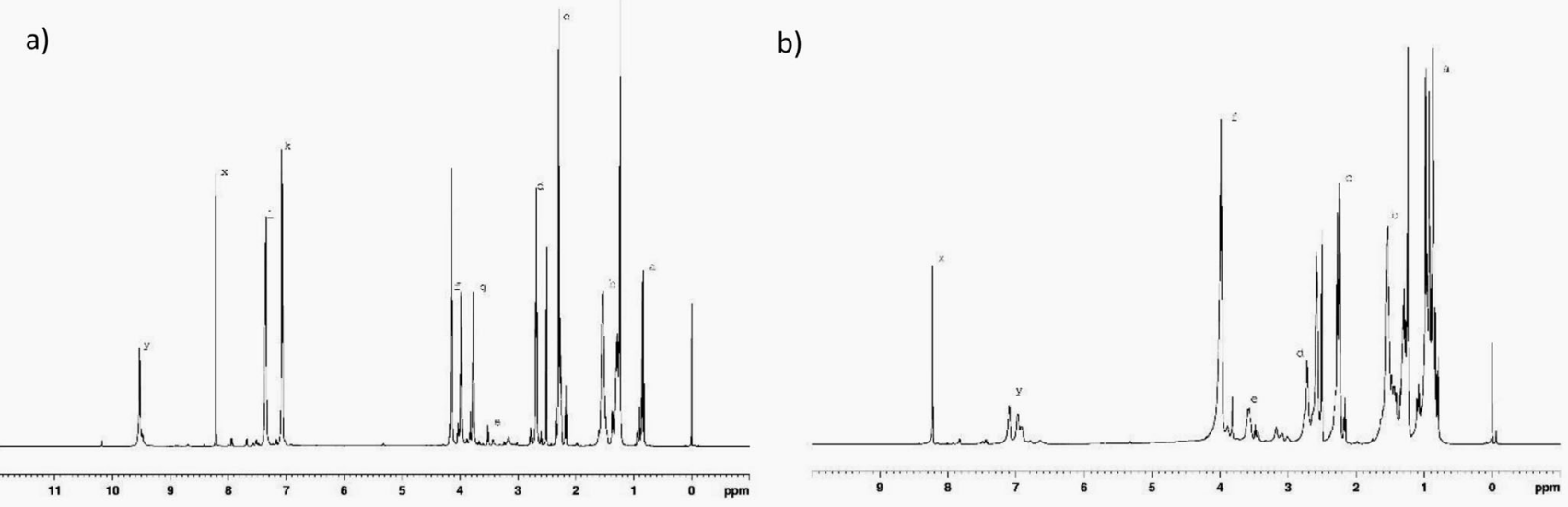

c)

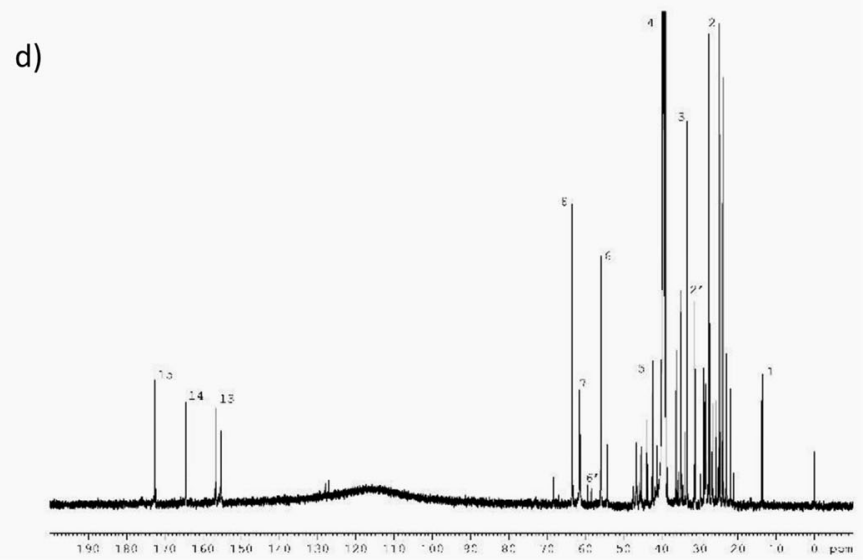

Fig. 1 NMR spectra of PU cationomers. a ${ }^{1} \mathrm{H}$ NMR spectrum of PU20A. $\mathbf{b}^{1} \mathrm{H}$ NMR spectrum of PU20B. ${ }^{13} \mathrm{C}$ NMR spectrum of PU20A. d ${ }^{13} \mathrm{C}$ NMR spectrum of PU20B cationomer

The results in Table 5 indicate that fluorinated PUs obtained from MDI are characterized by a higher degree of phase separation, compared to PU obtained by using IPDI, in contrast to unmodified PU where higher DPS index was found for IPDI-based polyurethane. It can be observed that an increase in the content of fluorinated polyol leads to a higher degree of phase separation, up to $15 \%$. Similar trends were observed by Zhao et al. [23] in fluorinated polyurethane elastomer based on fluoropoly(oxyalkylene) diol (FPOA). They found that with increasing FPOA/poly(butylene adipate glycol (PBA) mass ratio, the microphase separation also increased.

Here, samples of the PU A series with the highest FPD content have the lowest DPS. A similar trend has been observed for PU obtained using IPDI, where the lowest DPS was found for PU containing 20\% of a FPD. Again, the higher DPS has been revealed for PU with intermediate content of this polyol. However, it should be noted that DPS for IPDIbased fluorinated PU was lower than for MDI-based PU. Wang et al. [13] investigated the influence of fluorine incorporation on microphase separation in PU. They analysed three types of hydrogen bonds, namely $\mathrm{NH} \cdots \mathrm{O}=\mathrm{C}$ (hard segments — hard segments), and found that the hydrogen bond strength decreases with the introduction of fluorine. Hydrogen bonds between hard and soft segments enhance mixing of these segments and hinder microphase separation. The authors concluded that the interplay between types of hydrogen bonds is responsible for the extent of microphase separations. It suggests that in MDI-based fluorinated PUs, the hydrogen bonds between chains in hard segments are stronger that leads to higher DPS, while for IPDI-based PUs are slightly weaker. It should also be noted that for PUs based on MDI, the absorption bands from the free urethane $\mathrm{C}=\mathrm{O}$ group were found at ca. $1728 \mathrm{~cm}^{-1}$, while for PUs based on IPDI at ca. 1735 $\mathrm{cm}^{-1}$ which suggests stronger hydrogen interactions in MDIbased PUs and can be connected to the higher DPS in MDIbased PUs.

The results of the GPC analysis are shown in Fig. 5 and in Table 6 . The average molar mass of the obtained cationomers ranged from 15,000 to 20,000 with higher values obtained for PU synthesized based on MDI. The introduction of FPD in an amount of up to $10 \%$ causes an increase in average molar mass only for samples of the A series. This effect can be explained by the higher chemical reactivity of the - $\mathrm{NCO}$ 
Fig. 2 Structure of the obtained cationomer polyurethanes

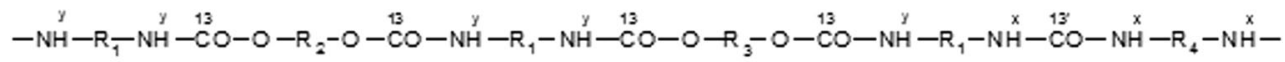

where:<smiles>[R]c1ccc(Cc2ccc(C)cc2)cc1</smiles>

(MDI) or<smiles>CCOOC(=O)NC1CCCC1(C)C(C)(C)C</smiles>

(IPDI)
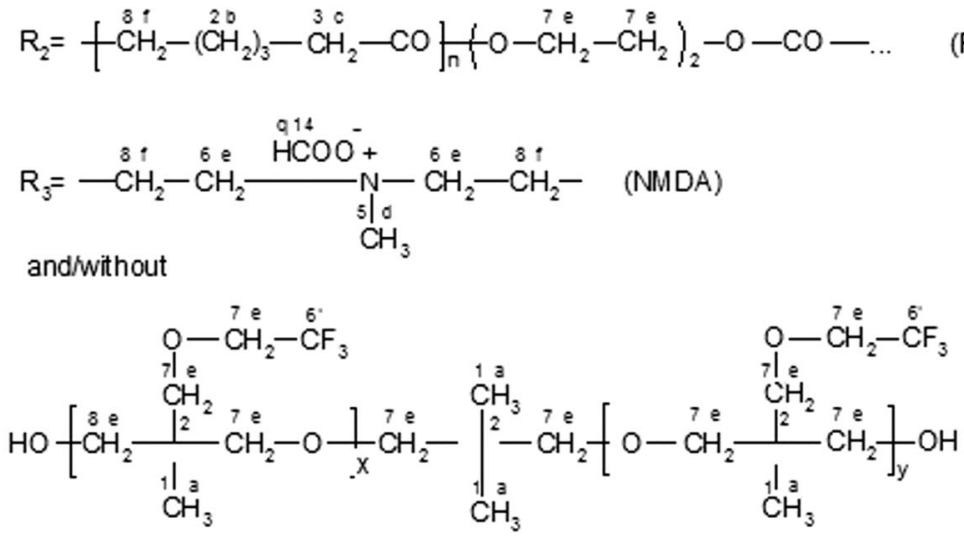

(FPD)
( HDA)

(DBTL)
$\mathrm{R}_{4}=-\stackrel{8}{\mathrm{C}} \mathrm{H}_{2}-\left(\stackrel{2}{\mathrm{C}} \mathrm{H}_{2}\right)_{4}-\stackrel{8}{\mathrm{C}} \mathrm{H}_{2}-$

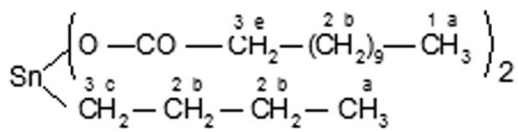

primary groups of the MDI diisocyanate. The molecular mass distribution in both cationomer series is similar. This indicates

Table 3 Analysis of integration of selected resonances in ${ }^{1} \mathrm{H}$ NMR spectra of PU cationomers obtained with MDI

\begin{tabular}{lll}
\hline Sample & $\begin{array}{l}\text { Integration relationship } \\
I_{\delta} / I_{k}\end{array}$ & $\begin{array}{l}\text { Integration relationship } \\
I_{f} / I_{k}\end{array}$ \\
\hline PU0A & 0.287 & 1.358 \\
PU5A & 0.309 & 1.749 \\
PU10A & 0.509 & 1.255 \\
PU15A & 0.536 & 1.567 \\
PU20A & 0.565 & 1.453 \\
\hline
\end{tabular}

where,

$I_{a}$, integration of the resonance for $\mathrm{CH}_{3}$ groups in PolyFox and DBTL catalyst) ( $a$ signal)

$I_{k}$, integration of the resonance for $\mathrm{CH}$ groups in MDI benzene ring ( $k$ signal)

$I_{f}$, integration of resonance for the $\mathrm{CH}_{2}$ groups in urethane segments - $\mathrm{NH}$ $\mathrm{CO}-\mathrm{O}-\mathrm{CH}_{2}^{-}(f$ signal $)$ that the components have reacted effectively under the applied synthesis conditions.

Examples of SEM microphotographs of both series of samples - without and with a maximum content of FPD, are shown in Fig. 6.

These images show substantial phase heterogeneity of the obtained films. Hard segment domains (bright) are dispersed in the soft segments (dark) or form larger agglomerates. On the presented SEM microphotographs, a few regions with different sizes have been marked and denoted with numbers $1-5$. The results of EDS analysis at these points are presented in Table 6. As expected, in the films obtained using fluorinated diol, the presence of fluorine atoms was confirmed, while the presence of $\mathrm{Sn}$ is connected with using dibutyltin dilaurate (DBTL) as a catalyst in PU synthesis. The different amount of $\mathrm{N}$ and $\mathrm{O}$ atoms in selected points of the same film (for example in 1-3 points of the PU0A sample) suggests microphase heterogeneity of the film top layer that can be seen in SEM microphotographs. It also should be noted that the signal in EDS analysis is recorded on the film surface, with max. $3 \mu \mathrm{m}$ 
Table 4 The IR spectrum interpretation of the synthesized cationomers

\begin{tabular}{|c|c|c|c|c|}
\hline \multirow[t]{2}{*}{ Type of band } & \multicolumn{4}{|c|}{ By Fig. 3} \\
\hline & \multicolumn{4}{|c|}{ Band positions, $\mathrm{cm}^{-1}$} \\
\hline $\mathrm{N}-\mathrm{H}$ valen. in urethane & 3311 & 3305 & 3323 & 3323 \\
\hline \multirow{2}{*}{$\underline{\mathrm{C}-\mathrm{H}}$ valen. in $\mathrm{CH}, \mathrm{CH}_{2}, \mathrm{CH}_{3}$ groups } & 2927 & 2925 & 29,256 & 2925 \\
\hline & 2854 & 2854 & 2860 & 2856 \\
\hline $\mathrm{C}=\mathrm{O}$ valen. $(\mathrm{I}$ amid band in urethane $)$ & 1705 & 1709 & 1698 & 1699 \\
\hline $\mathrm{C}-\mathrm{C}$ valen. in benzene ring & 1598 & 1599 & - & - \\
\hline $\mathrm{N}-\mathrm{H}$ def. (II amid band in urethane) & 1529 & 1533 & 1531 & 1533 \\
\hline$-\mathrm{CH}_{3}$ asym. def. & 1462 & 1463 & 1461 & 1461 \\
\hline $\mathrm{CH}_{2}$ scissoring or $\mathrm{C}-\mathrm{C}$ def. in benzene ring & 1412 & 1413 & - & - \\
\hline C-F very low stretching & - & $\approx 1280$ & - & $\approx 1280$ \\
\hline$\underline{\mathrm{C}-\mathrm{H}}$ def. in $\mathrm{CH}_{2}$ & 1309 & 1310 & 1305 & 1305 \\
\hline -NH-CO-O-C very strong valen. in urethane & 1218 & 1220 & 1237 & 1237 \\
\hline \multirow[t]{2}{*}{ Isopropyl or tertbutyl groups from IPDI } & - & - & 1157 & 1156 \\
\hline & - & - & 1192 & - \\
\hline \multirow[t]{2}{*}{$\mathrm{C}-\mathrm{O}-\mathrm{C}$ valen. in ether } & 1049 & 1051 & 1032 & 1032 \\
\hline & 1017 & 101 & & \\
\hline \multirow[t]{2}{*}{$\mathrm{C}-\mathrm{H}$ def. in benzene } & 916 & 916 & - & - \\
\hline & 951 & - & - & - \\
\hline $\mathrm{C}-\mathrm{H}$ def. in 1,4-disubstituted benzene ring from MDI & 815 & 816 & - & - \\
\hline$-\left(\mathrm{CH}_{2}\right)_{\mathrm{n}}-$ def. rocking type & 766 & 767 & 774 & 773 \\
\hline
\end{tabular}

depth. That can explain higher F content compared to the fluorine content in the whole sample (Table 1), due to fluorine atoms' tendency to migrate to the surface of the materials that has an impact on the hydrophobicity of the obtained polyurethanes.

Additional knowledge about the structure of synthesized PU was obtained from differential scanning calorimetry studies. DSC thermograms of synthesized PU films for first run(A) and (C) curves, and for second run-(B) and (D) profiles,

Table 5 Phase separation results and molecular mass of the fluorinated PU

\begin{tabular}{lllllll}
\hline Sample & $R$ & DPS & $M_{\mathrm{n}}$ & $M_{\mathrm{w}}$ & $M_{\mathrm{z}}$ & $\begin{array}{l}M_{\mathrm{w}} / \\
M_{\mathrm{n}}\end{array}$ \\
\hline PU0A & 1.127 & 0.530 & 10,330 & 15,490 & 19,430 & 1.50 \\
PU5A & 2.054 & 0.673 & 16,200 & 23,090 & 27,070 & 1.43 \\
PU10A & 1.917 & 0.657 & 18,170 & 24,970 & 28,590 & 1.37 \\
PU15A & 2.725 & 0.732 & 13,290 & 19,160 & 22,950 & 1.44 \\
PU20A & 0.707 & 0.414 & 12,390 & 18,350 & 22,250 & 1.48 \\
PU0B & 1.985 & 0.665 & 12,010 & 17,420 & 21,140 & 1.45 \\
PU5B & 0.221 & 0.181 & 10,910 & 16,470 & 20,420 & 1.51 \\
PU10B & 1.040 & 0.510 & 13,320 & 19,630 & 23,640 & 1.47 \\
PU15B & 1.666 & 0.625 & 9740 & 14,180 & 17,660 & 1.46 \\
PU20B & 0.697 & 0.411 & 10,830 & 16,230 & 20,160 & 1.49 \\
\hline
\end{tabular}
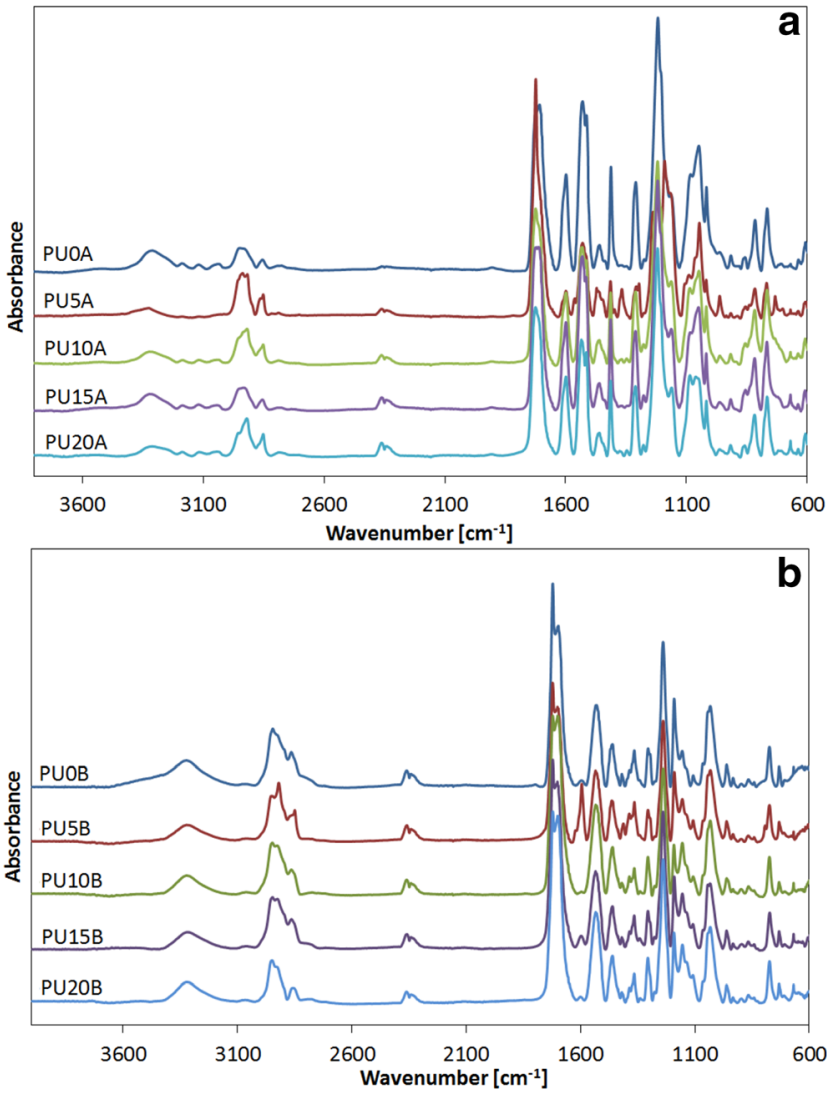

Fig. 3 FTIR spectra of the synthesized cationomers 

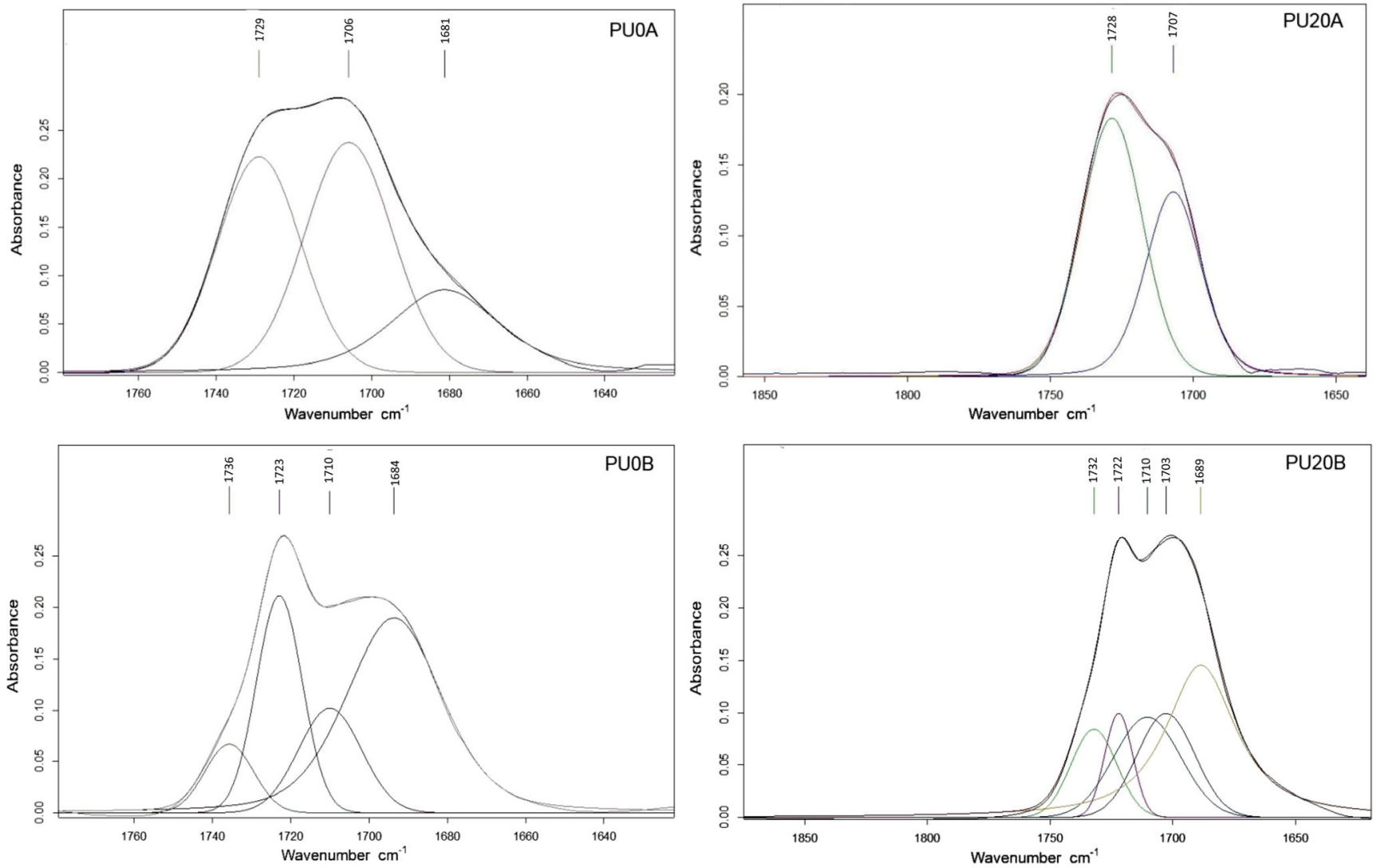

Fig. 4 Examples of deconvolution of $\mathrm{C}=\mathrm{O}$ bands FTIR spectra

are presented in Fig. 7. Activation plot of the glass transition for PU films determined from the frequency dependence of $T_{\mathrm{g}}$

is shown in Fig. 8, whereby the numerical results are given in Table 7.

Table 6 Elemental composition of selected polyurethane films

\begin{tabular}{|c|c|c|c|c|c|c|c|c|c|c|c|c|c|c|}
\hline \multirow[t]{2}{*}{ Sample } & \multirow[t]{2}{*}{ Area no. } & \multicolumn{13}{|c|}{ Atom, $\%$ weight } \\
\hline & & $\mathrm{C}-\mathrm{K}$ & $\begin{array}{l}\mathrm{N}- \\
\mathrm{K}\end{array}$ & $\begin{array}{l}\mathrm{O}- \\
\mathrm{K}\end{array}$ & $\begin{array}{l}\text { F- } \\
\text { K }\end{array}$ & $\begin{array}{l}\mathrm{Cl}- \\
\mathrm{K}\end{array}$ & $\begin{array}{l}\mathrm{Na}- \\
\mathrm{K}\end{array}$ & $\begin{array}{l}\mathrm{K}- \\
\mathrm{K}\end{array}$ & $\begin{array}{l}\mathrm{Mg}- \\
\mathrm{K}\end{array}$ & $\begin{array}{l}\mathrm{Ca}- \\
\mathrm{K}\end{array}$ & $\begin{array}{l}\mathrm{Al}- \\
\mathrm{K}\end{array}$ & $\begin{array}{l}\text { Si- } \\
\mathrm{K}\end{array}$ & $\begin{array}{l}\text { Sn- } \\
\text { L }\end{array}$ & Fe-K \\
\hline \multirow[t]{3}{*}{ PU0A } & 1 & 48.7 & 18.8 & 29.8 & - & - & - & - & - & - & - & - & 2.7 & - \\
\hline & 2 & 51.2 & 16.4 & 29.6 & - & - & - & - & - & - & - & - & 2.8 & - \\
\hline & 3 & 42.1 & 10.6 & 37.9 & - & - & - & - & - & 7.3 & 0.4 & 1.8 & 1.1 & - \\
\hline \multirow[t]{2}{*}{ PU20A } & 1 & Not marked & 3.2 & 11.6 & 0.3 & 27.7 & 22.1 & - & 0.5 & - & 0.4 & - & 7.6 & - \\
\hline & 2 & Not marked & 11.8 & 28.1 & 3.6 & 1.2 & - & - & 0.2 & - & 0.8 & - & - & - \\
\hline \multirow[t]{4}{*}{ PU0B } & 1 & Not marked & 8.7 & 26.1 & - & - & - & - & - & - & - & 1.3 & - & 28.6 \\
\hline & 2 & Not marked & 8.0 & 17.2 & - & 18.3 & 4.9 & 14.1 & - & - & - & 0.4 & - & - \\
\hline & 3 & Not marked & 5.6 & 27.6 & - & 12.2 & 6.5 & 8.5 & - & 4.3 & - & - & - & - \\
\hline & 4 & Not marked & 8.2 & 18.3 & - & 16.9 & 1.9 & 17.6 & - & - & - & - & - & - \\
\hline \multirow[t]{5}{*}{ PU20B } & 1 & Not marked & 6.2 & 25.1 & 1.6 & 0.5 & 0.7 & - & - & - & - & & & \\
\hline & 2 & Not marked & 11.2 & 26.0 & 3.8 & 0.3 & 0.4 & - & - & - & - & - & 5.5 & - \\
\hline & 3 & Not marked & 4.1 & 24.7 & 2.6 & 0.4 & - & - & - & - & - & 1.7 & 1.9 & - \\
\hline & 4 & Not marked & 10.2 & 27.5 & 3.5 & 0.4 & 0.4 & - & - & - & - & - & 5.9 & - \\
\hline & 5 & Not marked & 13.3 & 26.0 & 3.3 & 0.3 & 0.5 & - & - & - & - & - & 2.0 & - \\
\hline
\end{tabular}



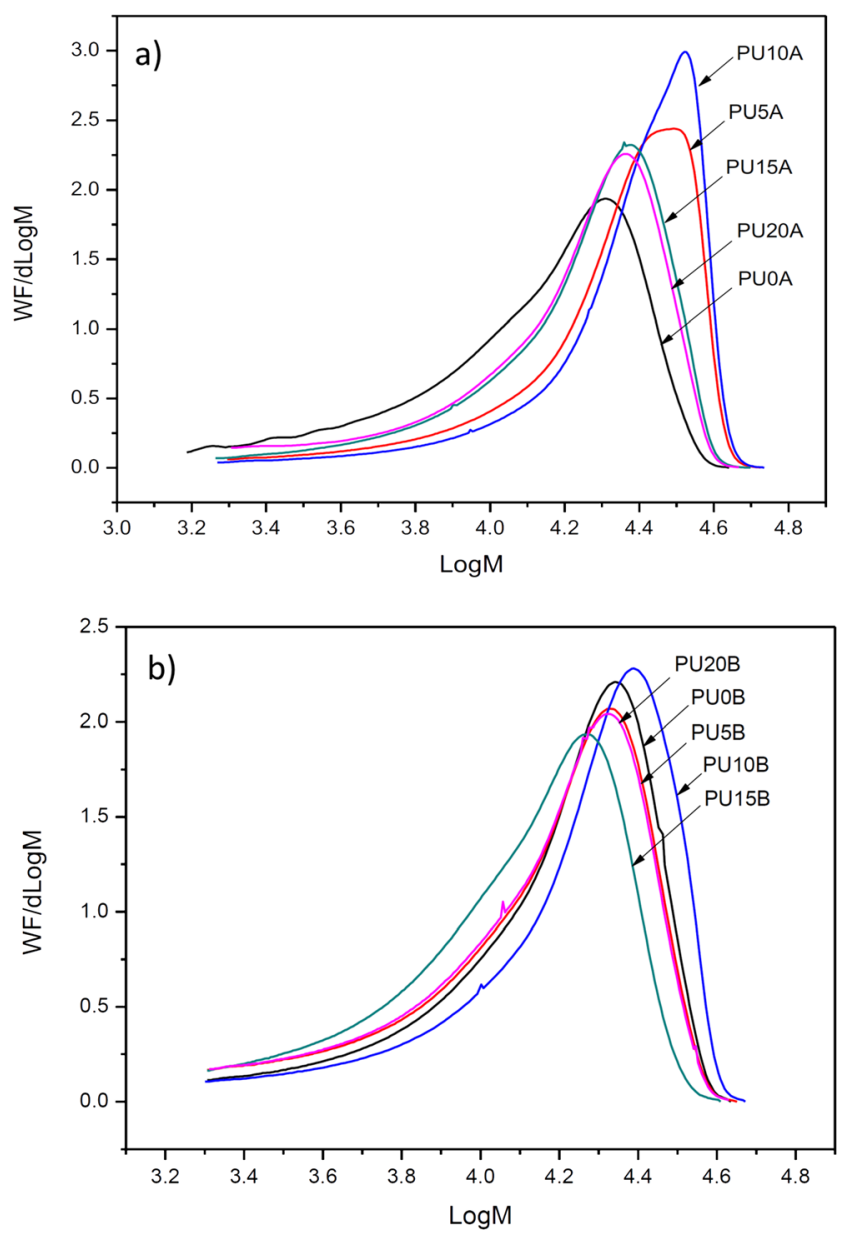

Fig. 5 Molecular mass distribution profiles of the synthesized PU cationomers. a PUA. b PUB

For MDI-based films, in the first heating run, glass transition can be seen and, next, partially overlapped melting of soft segments. Additionally, in the first heating run, two endothermic peaks in the range of $170-220{ }^{\circ} \mathrm{C}$ from melting of hard segments and phase separation were recorded. In the second heating run, only glass transition and melting of soft segments can be found. For IPDI-based PUs in the first heating run, glass transition and melting of soft segments, while for the second heating, only glass transition can be detected. As it can be seen from DSC curves, only the glass temperature of soft segments can be determined. For both series of samples, it can be seen that for PU containing $5 \%$ of fluorinated polyol glass temperature is similar to those of unmodified PUs. However, incorporation of higher amounts of fluorinated polyol leads to a decrease in glass temperature suggesting that fluorinated chain extender act as a plasticizer for PU soft segments. A similar effect was observed by Zhang et al. [24] who investigated properties of fluorinated PUs based on F-containing chain extender. The authors postulated that relatively small changes in glass transition temperature suggest no serious changes in phase separation in the obtained polymers. The downward trend of glass temperature can be attributed to the increase of the void volume between the macromolecular chains and overlapping effects associated with molecular mass changes.

An interesting effect was observed in DSC curves for both series in the first heating run where endothermic peaks in the range of $30-40{ }^{\circ} \mathrm{C}$ and $170-220^{\circ} \mathrm{C}$ were found (Fig. 8). Such effects can be attributed to the melting of well-formed crystallites in the soft and hard segment domains, respectively. In the second heating run, these effects have not been observed. It also should be noted that these effects were smaller for PUA series. Noteworthy, WAXD measurements confirmed the presence of the crystalline phase in the obtained materials only for the PUB series, which is visible on diffractograms showed in Figs. 9 and 10.

We expected rather a tendency for the formation of ordered structures in PUs obtained using MDI with symmetrical aromatic structure. Meanwhile, the opposite effect has been observed - the samples PUB, synthesized using acyclic IPDI, contain crystalline phase (ca. 30\%), while PUA was amorphous (Table 8). The effect can be attributed to the higher mobility of polymer chains due to conformational lability of cyclopropane rings that are present in hard segments of PUB.

It was confirmed by the lower activation energy of glass transition for type B fluorinated PUs (Table 7). Moreover, it leads to denser spatial packing of PU chains and favours partial crystallization of the formed films.

Next, based on TOPEM DSC results, the activation energy of glass transition of soft segments has been calculated according to the procedure described in Ref. [25, 26]. Arrhenius plots and results of the calculation are presented in Fig. 8. Generally, higher activation energy was found for MDI-based PUs, especially for samples containing higher amounts of fluorinated polyol. A similar trend has been observed for IPDI-based PUs; however, the values of activation energy are lower. The lowest activation energy has been found for unmodified PUs. That can be attributed to the stronger hydrogen bonding of soft segment microdomains by hard segments after the incorporation of fluorinated polyol.

The determined values of contact angles and the $\operatorname{FSE}\left(\gamma_{\mathrm{S}}\right)$, as well as their components $\left(\gamma_{\mathrm{S}}{ }^{\mathrm{d}}\right.$ and $\left.\gamma_{\mathrm{S}}{ }^{\mathrm{p}}\right)$ calculated on their basis are given in Table 9.

From the results presented in Table 9, it can be seen that an increase of fluorine content leads to a significant FSE decrease in both series of the obtained films. SEP of PU cationomers films without $\mathrm{F}$ atoms ( $\mathrm{P} 0 \mathrm{~A}$ and $\mathrm{P} 0 \mathrm{~B}$ ) was ca. $50 \mathrm{~mJ} / \mathrm{m}^{2}$ which reveals substantial hydrophilicity, while gradual increase of fluorine content at the surface cause SEP value to decrease to ca. $20 \mathrm{~mJ} / \mathrm{m}^{2}$ clearly 

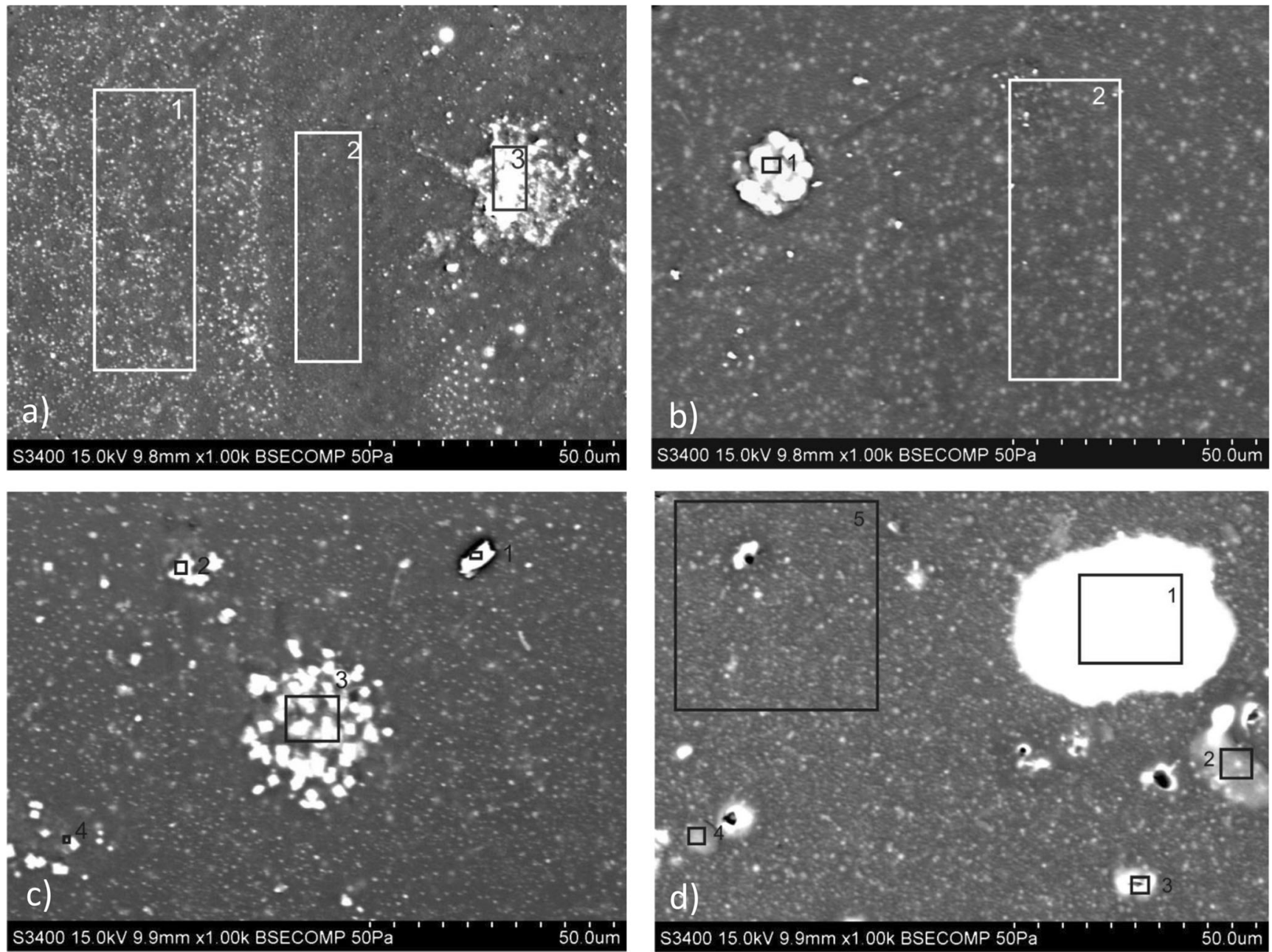

Fig. 6 SEM micrographs of PU cationomers. a PU0A film (areas 1-3 are marked). b PU20A (areas 1 and 2 are marked). c PU0B (areas 1-4 are marked). d PU20B (areas 1-5 are marked)

indicating the hydrophobic character of F-containing films. The most hydrophobic are films in PUA series containing higher amounts of $\mathrm{F}$ atoms. These observations were confirmed in water uptake investigations (Table 9) - it was observed that PUA films are much less wettable, compared to PUB films.
Table 7 Glass transition of PU samples (second heating run) and activation energy of glass transition of soft segments for synthesized PUs

\begin{tabular}{|c|c|c|c|c|c|}
\hline \multirow[t]{2}{*}{ Sample } & \multicolumn{2}{|c|}{$\begin{array}{l}\text { Glass transition of soft segments } \\
\text { (DSC) }\end{array}$} & \multicolumn{2}{|c|}{$\begin{array}{l}\text { Glass transition of soft segments (TOPEM } \\
\text { DSC, reversing heat flow) }\end{array}$} & \multirow[t]{2}{*}{$E_{\mathrm{a}}, \mathrm{kJ} / \mathrm{mo}$} \\
\hline & $T_{\mathrm{g}}$ (inflection point), ${ }^{\circ} \mathrm{C}$ & $\begin{array}{l}\Delta C_{\mathrm{p}}, \\
\mathrm{J} / \mathrm{g} \cdot \operatorname{deg}\end{array}$ & $E_{\mathrm{a}}, \mathrm{kJ} / \mathrm{mol}$ & $\begin{array}{l}\Delta C_{\mathrm{p}}, \\
\mathrm{J} / \mathrm{g} \cdot \operatorname{deg}\end{array}$ & \\
\hline PU0A & -32 & 0.212 & 107 & 0.190 & 107 \\
\hline PU5A & -31 & 0.320 & 115 & 0.250 & 115 \\
\hline PU10A & -36 & 0.340 & 401 & 0.351 & 401 \\
\hline PU15A & -37 & 0.350 & 403 & 0.378 & 403 \\
\hline PU20A & -42 & 0.110 & 242 & 0.437 & 242 \\
\hline PU0B & -11 & 0.260 & 99 & 0.338 & 99 \\
\hline PU5B & -40 & 0.161 & 125 & 0.118 & 125 \\
\hline PU10B & -27 & 0.121 & 138 & 0.119 & 138 \\
\hline PU15B & -40 & 0.126 & 133 & 0.260 & 133 \\
\hline PU20B & -30 & 0.128 & 105 & 0.117 & 105 \\
\hline
\end{tabular}



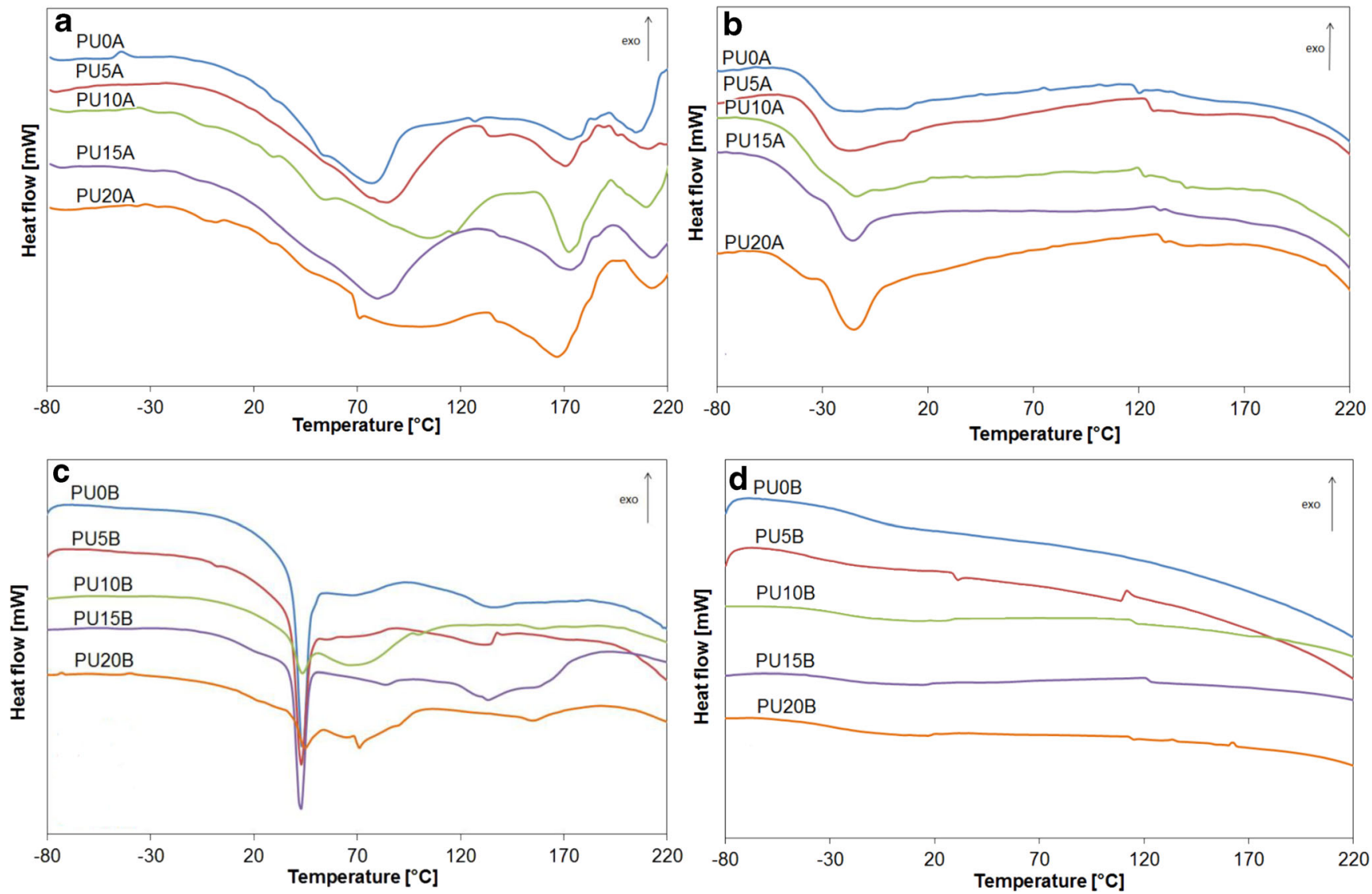

Fig. 7 DSC thermograms of synthesized PU films. a, $\mathbf{c}$ First run. b, d Second run

Thermogravimetric analysis results for the PUA and PUB samples are presented in Fig. 11. Due to the overlapping of effects, more readable are DTG curves that allow to observe differences in the thermal stability of both PU series. Thermal stability parameters are presented in Table 10.

From the obtained results, one can see that the obtained PU films are thermally stable up to ca. $200{ }^{\circ} \mathrm{C}$, and the maximum mass loss was at ca. $300{ }^{\circ} \mathrm{C}$. In DTG thermograms, two characteristic maxima were observed, which correspond to the temperatures of initial degradation of hard segments $\left(\mathrm{DTG}_{\max 1}\right)$ and, at a substantially higher temperature, degradation of soft segments $\left(\mathrm{DTG}_{\max 2}\right)$ [27]. These characteristic temperatures depend on F content to a small extent, which can be explained by low fluorine content in PU elastomer. However, a more detailed analysis shows that with fluorine content increase, the thermal degradation rate in $\mathrm{DTG}_{\mathrm{mx}}$ decreased. However, this observation should be verified in future detailed studies on kinetics of degradation [28].

The mechanical properties presented in Fig. 12 and Table 9 are important when considering the applications of the obtained films, for example as hydrophobic protective membranes.
Analysis of results shows that the investigated PUA films are characterized by tensile strength ca. $30 \mathrm{MPa}$ and relative elongation over $100 \%$ with Young modulus ca. $150 \mathrm{MPa}$, showing their elastomeric character. The best mechanical properties were observed in PU5A-PU15A in films formed from cationomers with molecular masses of 23,000-19,200 and fluorine soft segment content in the range of 5-15 Stress at break $\left(\sigma_{\mathrm{r}}\right)$ values for B series films were already much worse and difficult to measure. In this case, acceptable maximal content of the element fluorine would be ca. $0.30 \%$ weight in PU cationomers (Table 1). The fluorinated polyol plasticizing effect found in DSC analysis was therefore confirmed in mechanical tests.

\section{Conclusions}

Incorporation of $5-15 \%$ fluorinated polyol as a soft segments in linear polyurethane cationomers synthesized using MDI or IPDI diisocyanate, PCL polyester and MDEA amine leads to substantial changes on the strength of hydrogen bonds and in consequence degree of phase separation. For both series of samples, it can be seen that for PU containing 5\% of FPD the Tg is similar to those of 

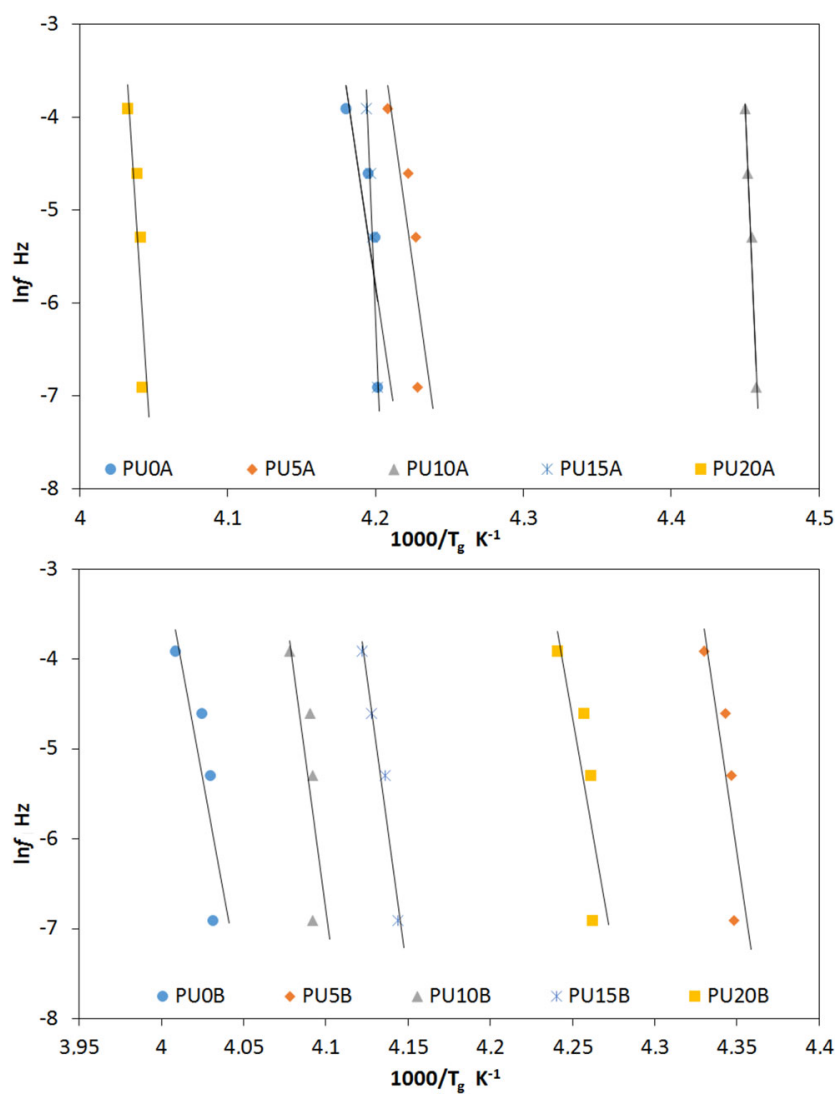

Fig. 8 Activation plot of the glass transition for PU films determined from the frequency dependence of $T_{\mathrm{g}}$
Table 8 Degree of crystallinity for B series cationomers

\begin{tabular}{lll} 
Sample & $\begin{array}{l}\text { Degree of crystallinity, } \% \\
\text { based } 2 \Theta=(20.5-26)^{\circ}\end{array}$ & $\begin{array}{l}\text { Degree of crystallinity, } \\
\% \text { based on the entire } \\
\text { measuring range }(0-28)^{\circ}\end{array}$ \\
\hline PU0B & 24 & 29 \\
PU5B & 37 & 54 \\
PU10B & 8 & 24 \\
PU15B & 27 & 35 \\
PU20B & 21 & 32 \\
\hline
\end{tabular}

unmodified PUs. However, incorporation of higher amounts of FPD leads to a decrease in $T_{\mathrm{g}}$ suggesting that this polyol acts as a plasticizer for PU soft segments; indeed, it was reflected by changes in the mechanical properties of the prepared films. Introduced $\mathrm{F}$ shows the ability to migrate to the top layer, which leads to $5-7$ times increase of its content in the film's top layers and causes a significant decrease in FSE and water uptake.

TOPEM DSC analyses showed that generally the higher activation energy of glass transition of soft segments was found for MDI-based PUs, especially for samples containing higher amounts of FPD. A similar trend has been observed for IPDI-based PUs; however, the values of activation energy are
Fig. 9 WAXD diffractograms for PUA films

Fig. 10 WAXD diffractograms for PUB films
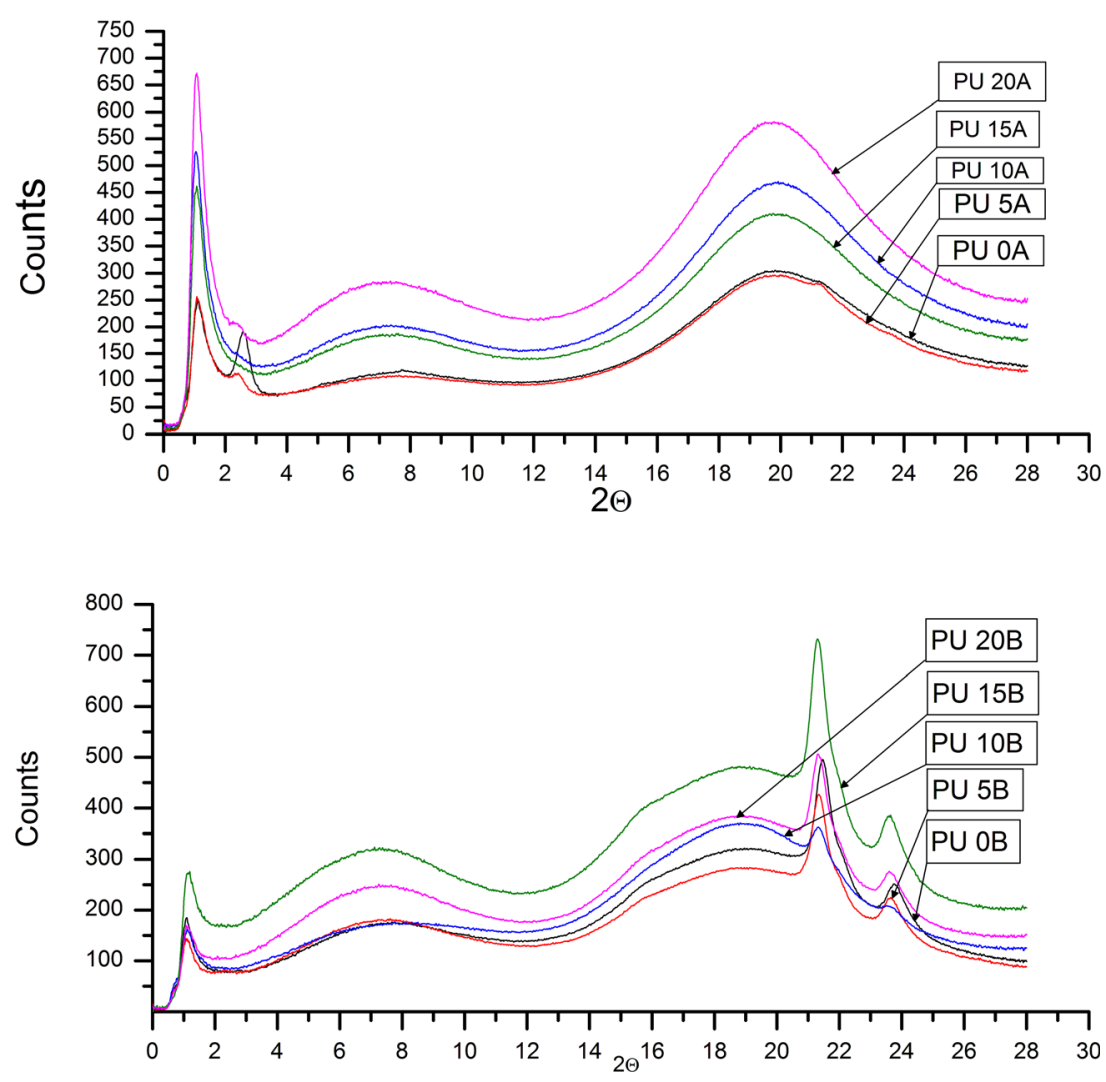
Table 9 Mechanical and surface properties of the polyurethane cationomer films

Sample Breaking stress, $\sigma_{\mathrm{r}}$ Elongation at break $\varepsilon_{\mathrm{r}}$ Young's modulus Contact angle for standard liquid $(\Theta),{ }^{\circ}$

\begin{tabular}{|c|c|c|c|c|c|c|c|c|c|}
\hline & \multirow[b]{2}{*}{$\mathrm{MPa}$} & \multirow[b]{2}{*}{$\%$} & \multirow[b]{2}{*}{$\mathrm{MPa}$} & \multicolumn{2}{|c|}{$\longrightarrow$} & & \\
\hline & & & & Water & Diiodomethane & $\gamma_{\mathrm{S}}$ & $\gamma_{\mathrm{S}}^{\mathrm{d}}$ & $\gamma_{\mathrm{S}}^{\mathrm{P}}$ & \\
\hline PU0A & 7 & 100 & 145 & $79.7 \pm 2.1$ & $41.6 \pm 1.5$ & $44.1 \pm 0.2$ & 39.5 & 4.6 & 23.9 \\
\hline PU5A & 20 & 350 & 160 & $87.2 \pm 1.5$ & $57.8 \pm 2.2$ & $34.5 \pm 0.1$ & 30.6 & 3.9 & 21.5 \\
\hline PU10A & 33 & 373 & 390 & $92.3 \pm 2.0$ & $64.4 \pm 2.0$ & $29.5 \pm 0.2$ & 26.5 & 3.0 & 16.7 \\
\hline PU15A & 10 & 290 & 110 & $96.4 \pm 1.8$ & $68.8 \pm 2.1$ & $26.0 \pm 0.1$ & 23.8 & 2.2 & 15.4 \\
\hline PU20A & 7 & 182 & 175 & $105.9 \pm 2.2$ & $72,0 \pm 2.5$ & $22.4 \pm 0.2$ & 21.9 & 0.5 & 13.5 \\
\hline PU0B & 4 & 650 & Not measured & $55.9 \pm 2.5$ & $13.0 \pm 3.0$ & $55.0 \pm 0.2$ & 41.0 & 14.0 & 47.8 \\
\hline PU5B & 12 & 650 & & $67.6 \pm 1.6$ & $34.0 \pm 1.5$ & $45.6 \pm 0.1$ & 35.9 & 9.7 & 40.1 \\
\hline PU10B & 9 & 500 & & $73.5 \pm 1.7$ & $46.8 \pm 1.8$ & $38.9 \pm 0.3$ & 30.2 & 8.7 & 32.4 \\
\hline PU15B & 1 & 900 & & $81.3 \pm 1.5$ & $65.0 \pm 2.0$ & $29.1 \pm 0.2$ & 20.7 & 8.4 & 23.7 \\
\hline PU20B & 2 & 700 & & $93.9 \pm 2.0$ & $76.3 \pm 3.0$ & $20.9 \pm 0.1$ & 16.5 & 4.4 & 20.6 \\
\hline
\end{tabular}

Surface free energy and its Water uptake, \% Surface free energy components, $\mathrm{mJ} / \mathrm{m}^{2}$
Table 10 Comparison of thermal durability of the polyurethane films

\begin{tabular}{|c|c|c|c|c|c|c|}
\hline \multirow[t]{2}{*}{ Sample } & \multicolumn{4}{|c|}{ Temperature of the $\%$ weight loss, ${ }^{\circ} \mathrm{C}$} & \multirow{2}{*}{$\begin{array}{l}\mathrm{DTG}_{\max } \cdot \\
{ }^{\circ} \mathrm{C}\end{array}$} & \multirow{2}{*}{$\begin{array}{l}\text { The rate of weight loss in } \mathrm{DTG}_{\max } \text {. } \\
\mathrm{mg} /{ }^{\circ} \mathrm{C}\end{array}$} \\
\hline & $T_{1 \%}$ & $T_{5 \%}$ & $T_{10 \%}$ & $T_{50 \%}$ & & \\
\hline PU0A & 191 & 216 & 230 & 316 & $241 ; 301 ; 387$ & 0.00310 \\
\hline PU5A & 140 & 208 & 227 & 302 & $271 ; 390$ & 0.00385 \\
\hline PU10A & 110 & 203 & 225 & 312 & $270 ; 393$ & 0.00370 \\
\hline PU15A & 122 & 200 & 223 & 302 & $255 ; 304 ; 393$ & 0.00265 \\
\hline PU20A & 120 & 200 & 223 & 306 & $258 ; 305 ; 393$ & 0.00290 \\
\hline PU0B & 113 & 246 & 258 & 297 & $290 ; 406$ & 0.01000 \\
\hline PU5B & 120 & 229 & 247 & 307 & $308 ; 413$ & 0.00910 \\
\hline PU10B & 172 & 231 & 250 & 296 & $283 ; 410$ & 0.00860 \\
\hline PU15B & 109 & 176 & 230 & 290 & $290 ; 409$ & 0.00886 \\
\hline PU20B & 146 & 221 & 240 & 297 & $292 ; 418$ & 0.00820 \\
\hline
\end{tabular}
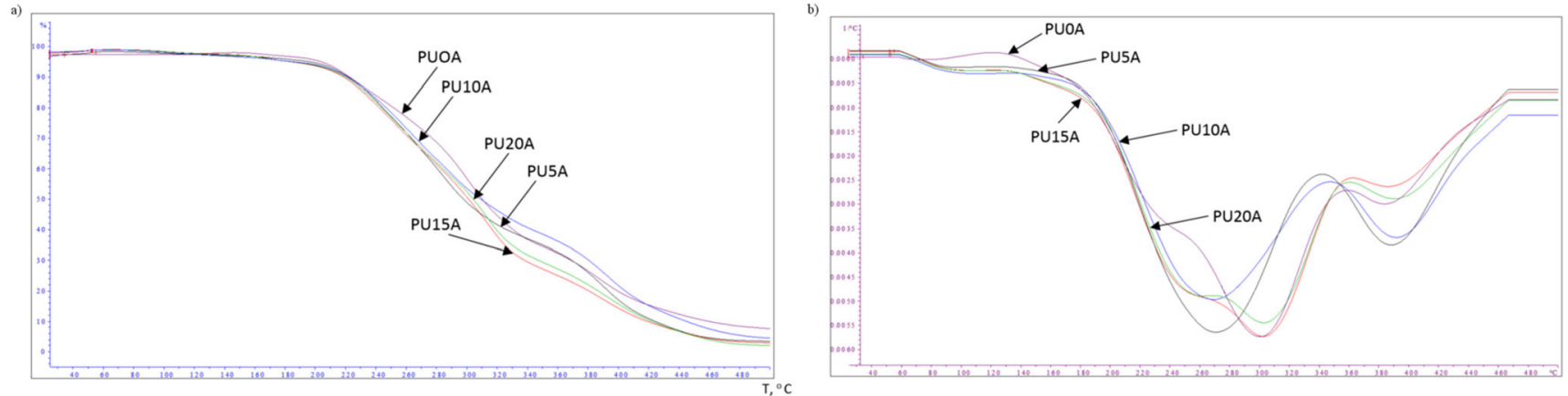

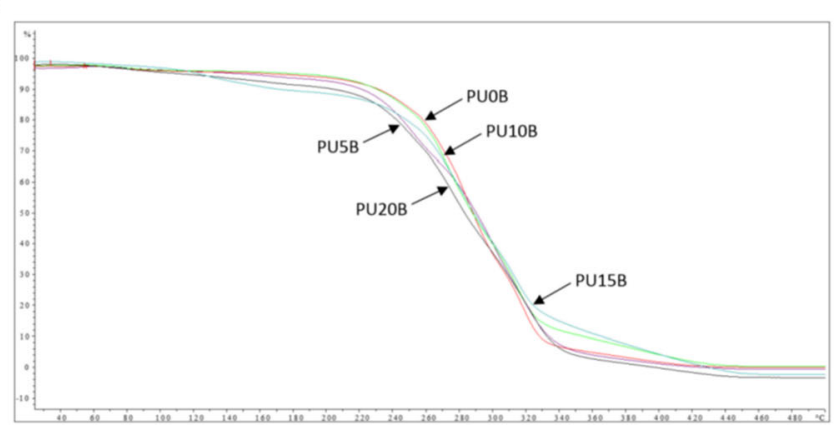

Fig. 11 TG and DTG thermograms for the PU films. a, b For PUA. c, d For PUB

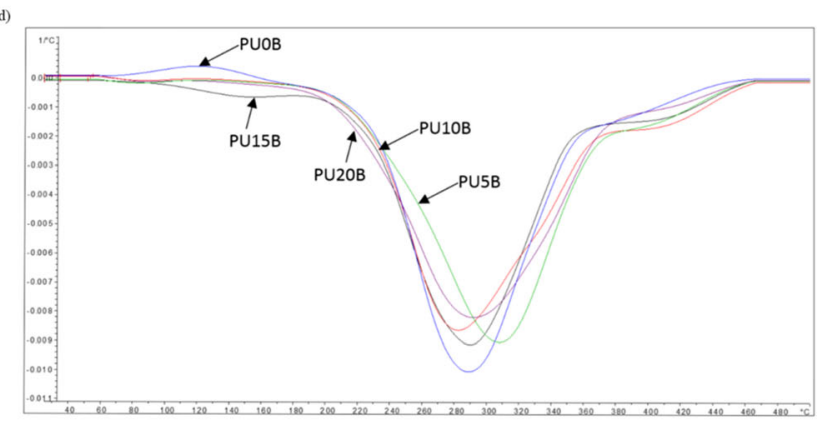


Fig. 12 Stress-strain curves for PUA series films

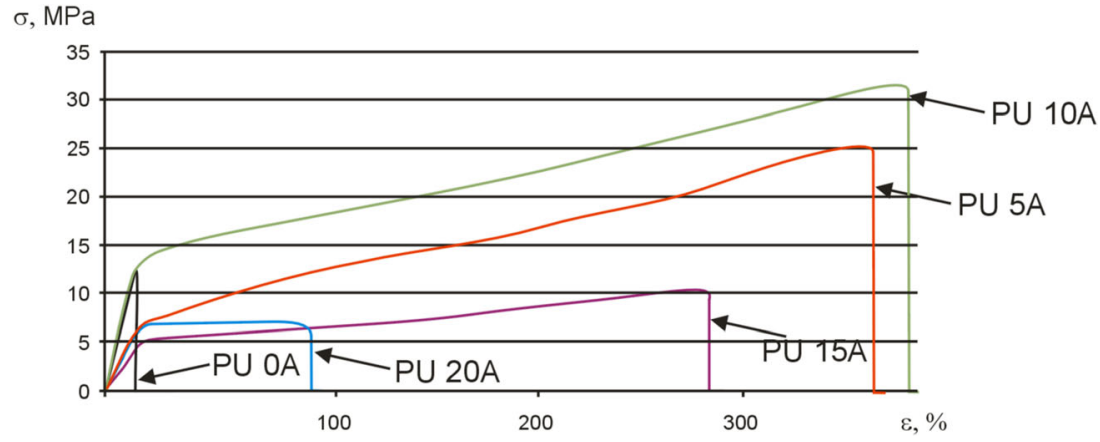

$\sigma, \mathrm{MPa}$ Biodegradable polyurethanes: novel effects of the fluorinecontaining chain extender on the thermal, physical and water vapor permeation properties. J Polym Res 25:227. https://doi.org/10. 1007/s10965-018-1607-2

5. Zhang R, Ren Y, Yan YD, Guo P, Li I (2017) Synthesis of hydrophobic fluorinated polyurethanes and their properties of resistance to cavitation and wear. Prog Org Coat 104:11-19. https://doi.org/ 10.1016/j.porgcoat.2016.12.002

6. Wen J, Sun Z, Fan H, Chena Y, Yan J (2019) Synthesis and characterization of a novel fluorinated waterborne polyurethanes. Prog Org Coat 131:291-300. https://doi.org/10.1016/j.porgcoat.2019. 02.029

7. Wen J, Sun Z, Xiang J, Fan H, Chen Y, Jang J (2019) Preparation and characteristics of waterborne polyurethane with various lengths of fluorinated side chains. Appl Surf Sci 494:610-618. https://doi. org/10.1016/j.apsusc.2019.07.170

8. Wang Y, An Q, Yang B (2019) Synthesis of UV-curable polyurethane acrylate modified with polyhedral oligomeric silsesquioxane and fluorine for iron cultural relic protection coating. Prog Org Coat 136:105235. https://doi.org/10.1016/j.porgcoat.2019.105235

9. Cai Q, Huang J, Weng R, Liu S (2018) Preparation and surface properties of silicon-containing waterborne polyurethane functionalized with fluorine-containing acrylate and micro nano-silica. J Wuuhang Univ Technol Mate Sci Ed 33:233-241. https://doi.org/ 10.1007/s11595-018-1811-2

10. Nazarov VG, Stolyarov VP, Petrova GN, Gryaznov VI, Buznik VM (2016) Special features of surface fluorination of thermoplastic polyurethane elastomers and its effect on the polymer properties. Inorg Mater Appl Res 7:773-778. https://doi.org/10.1134/ S207511331605018X

11. Król B, Pielichowska KP, Kędzierski M (2019) Polyurethane cationomer films as ecological membranes for building industry. Prog Org Coat 130:83-92. https://doi.org/10.1016/j.porgcoat.2019. 01.045

12. Król P, Król B (2020) Structure, properties and applications of the polyurethane ionomers. J Mater Sci 55:73-87. https://doi.org/10. 1007/s10853-019-03958-y

13. Wang X, Xu J, Li L, Liu Y, Li Y, Dong Q (2016) Influences of fluorine on microphase separation in fluorinated polyurethanes. Polymer 98:311-319. https://doi.org/10.1016/j.polymer.2016.06. 039

14. Wang X, Hu J, Li Y, Zhang J, Ding Y (2015) The surface properties and corrosion resistance of fluorinated polyurethane coatings. J Fluor Chem 176:14-19. https://doi.org/10.1016/j.jfluchem.2015. 04.0027

15. Tan D, Zhang X, Li J, Tan H, Fu Q (2012) Modification of poly(ether urethane) with fluorinated phosphorylcholine polyurethane for improvement of the blood compatibility. J Biomed Mater Res. A 100:380-387. https://doi.org/10.1002/jbm.a.33191 
16. Król B, Król P, Pikus S, Chmielarz P, Skrzypiec K (2010) Synthesis and characterisation of coating polyurethane cationomers containing fluorine built-in hard urethane segments. Coll Polym Sci 288:1255-1269. https://doi.org/10. 1007/s00396-010-2244-4

17. Król P, Król B, Lechowicz JB (2014) Modelling the surface free energy parameters of polyurethane coats-part 2 . Waterborne coats obtained from cationomer polyurethanes. Coll Polym Sci 292:1051-1059. https://doi.org/10.1007/ s00396-013-3156-x

18. Król P, Król B (2012) Surface free energy of polyurethane coatings with improved hydrophobicity. Coll Polym Sci 290:879-893. https://doi.org/10.1007/s00396-012-2598-x

19. Li J-W, Lee H-T, Tsai H-A, Suen M-C, Chiu C-W (2018) Synthesis and properties of novel polyurethanes containing long-segment fluotinated chain extenders. Polymers (Basel) 10:1292. https://doi. org/10.3390/polym10111292

20. Seymour RW, Estes GM, Cooper SL (1970) Infrared studies of segmented polyurethan elastomers. I. Hydrogen Bonding. Macromolecules. 3:579-583

21. Żenkiewicz M (2006) A new method of free surface energy analysis of polymeric materials calculated using the methods of OwensWendt and Neumann. Polimery (Polish) 51:584-587. https://doi. org/10.14314/polimery.2006.584
22. Zisman WA (1964) Relation of the equilibrium contact angle to liquid and solid constitution. Contact angle, wettability, and adhesion. Advances in Chemistry. Am Chem Soc 43:1-5

23. Zhao X, Ding J, Ye L (2014) Structure and solvent-resistant property of fluorinated polyurethane elastomer. J Fluor Chem 159:38 47. https://doi.org/10.1016/j.jfluchem.2013.12.012

24. Zhang L, Kong Q, Kong F, Liu T, Qian H (2020) Synthesis and surface properties of novel fluorinated polyurethane base on Fcontaining chain extender. Polym Advan Tech 31:619-626. https://doi.org/10.1002/pat.4802

25. Król B, Pielichowska K, Król CP (2017) Polyurethane cationomers modified by polysiloxane. Polym Advan Tech 28:1366-1374. https://doi.org/10.1002/pat.4013

26. Chen K, Harris K, Vyazovkin S (2007) Tacticity as a factor contributing to the thermal stability of polystyrene. Macromol Chem Phys 208:2525-2532. https://doi.org/10.1002/macp.200700426

27. Chattopadhyay DK, Webster DC (2009) Thermal stability and flame retardancy of polyurethanes. Prog Polym Sci 34:10681133. https://doi.org/10.1016/j.progpolymsci.2009.06.002

28. Opfermann J, Kaisersberger E (1992) An advantageous variant of the Ozawa-Flynn-Wall analysis. Thermochim Acta 203:167-175. https://doi.org/10.1016/0040-6031(92)85193-Y

Publisher's Note Springer Nature remains neutral with regard to jurisdictional claims in published maps and institutional affiliations. 